\title{
Development of Protective Coatings for Co-Sequestration Processes and Pipelines
}

\section{Final Scientific Report}

\author{
Reporting Period: \\ Start Date December 2009 \\ End Date November 2011 \\ Principle Authors: \\ Professor Gordon Bierwagen \\ Graduate Research Assistant Yaping Huang
}

Report Issued

February 2012

DOE Award \#DE-FE0002054

North Dakota State University

Coatings and Polymeric Materials

1735 Research Park Drive

Fargo, North Dakota 58105 


\section{Disclaimer}

This report was prepared as an account of work sponsored by an agency of the United States Government. Neither the United States Government nor any agency thereof, nor any of their employees, makes any warranty, express or implied, or assumes any legal liability or responsibility for the accuracy, completeness, or usefulness of any information, apparatus, product, or process disclosed, or represents that its use would not infringe privately owned rights. Reference herein to any specific commercial product, process, or service by trade name, trademark, manufacturer, or otherwise does not necessarily constitute or imply its endorsement, recommendation, or favoring by the United States Government or any agency thereof. The views and opinions of authors expressed herein do not necessarily state or reflect those of the United States Government or any agency thereof. 


\begin{abstract}
The program, entitled "Development of Protective Coatings for Co-Sequestration Processes and Pipelines", examined the sensitivity of existing coating systems to supercritical carbon dioxide (SCCO2) exposure and developed new coating system to protect pipelines from their corrosion under SCCO2 exposure. A literature review was also conducted regarding pipeline corrosion sensors to monitor pipes used in handling co-sequestration fluids. Research was to ensure safety and reliability for a pipeline involving transport of SCCO2 from the power plant to the sequestration site to mitigate the greenhouse gas effect. Results showed that one commercial coating and one designed formulation can both be supplied as potential candidates for internal pipeline coating to transport SCCO2.
\end{abstract}

\title{
Table of Contents
}

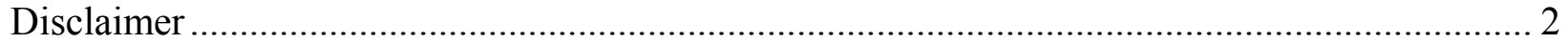

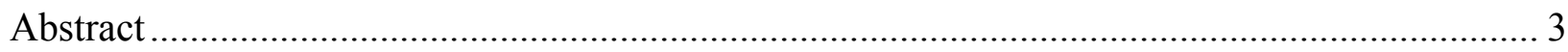

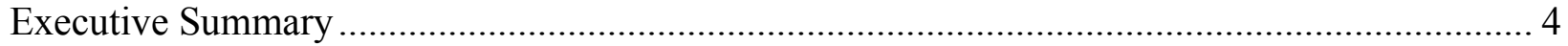

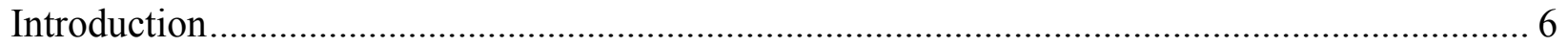

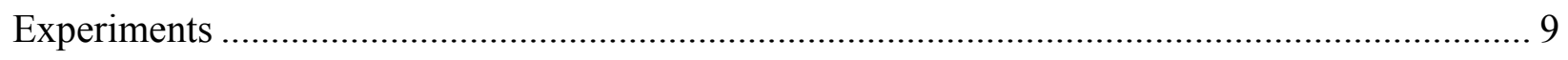

Performance of TZ ${ }^{\mathrm{TM}} 904$ in supercritical carbon dioxide............................................ 15

Performance of DevChem ${ }^{\mathrm{TM}} 253$ in supercritical carbon dioxide ...................................... 19

Performance of Scotchkote ${ }^{\mathrm{TM}} 323$ in supercritical carbon dioxide...................................... 22

Performance of Scotchkote ${ }^{\mathrm{TM}} 345$ in supercritical carbon dioxide........................................ 25

Performance of designed polymers in supercritical carbon dioxide .................................. 29

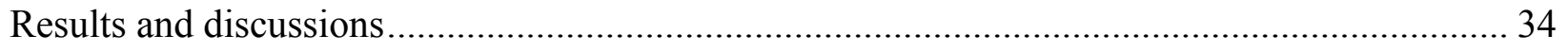

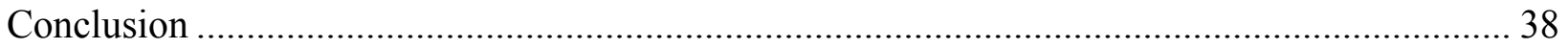




\section{Executive Summary}

Goals of project were to fabricate internal coatings for pipeline involving transport of the supplied multi component gas mixture from the power plant to the sequestration site. The project started with literature review on polymers resistive to $\mathrm{SCCO} 2$, and pipeline steel corrosion phenomena under SCCO2 condition. With the understanding SCCO2 resistive organic polymers, several commercial coatings were chosen as a preliminary investigation. With the consideration of functional groups and backbone structures to resist SCCO2, Polyoil ${ }^{\text {TM }} 130$ based coating formulations were prepared. Then, the investigations on corrosion behaviors of several commercial coatings exposed to $\mathrm{SCCO} 2$ were conducted by electrochemical impedance method, a common method used for corrosion process investigation under SCCO2 exposure. The measurements under SCCO2 exposure were used to evaluate protection ability of organic coatings, which could be used for protective coatings for pipelines if service life could meet the requirements of pipeline life. To ensure the safety and good maintenance of handling pipeline transportation, research regarding corrosion monitoring sensors was reviewed to give some recommendations for sensors used in pipelines to transport SCCO2.

Unique results in the project are listed in the followings.

1. A test protocol for $\mathrm{SCCO} 2$ resistance was developed. In the investigation of SCCO2 resistance, the samples were exposed to different conditions of SCCO2 of different temperatures and different pressures with different duration periods. After the exposure, the samples were characterized with their weights and thicknesses, and were visually inspected with the blisters and the pores on the surface.

Electrochemical impedance spectroscopy was also used to test possible sample failures under the exposure. With the combination of characterization methods, SCCO2 resistance ability can be obtained.

2. Failure processes and mechanisms of coating exposed to $\mathrm{SCCO} 2$ were discovered. In the investigation of SCCO2 resistance, the samples exposed to SCCO2 were found to form blisters or porous structures on the surface. The mechanisms of the blister or porous structure formation may be due to SCCO2 diffusing into organic coatings, and changing into $\mathrm{CO} 2$ when pressure was released, which was trapped into coatings. If the coatings were resilient, blisters were formed. If coatings were brittle, porous structures were formed.

3. Organic coatings were found in commercial and designed in lab to serve protective coatings for pipeline transportation of SCCO2. Organic coatings, to be used as protective coatings for SCCO2 transportation, should be SCCO2 resistant, good adhesion property to metal substrate, good resilient properties, and high glass transition temperature. In the investigation, $3 \mathrm{M}$ Scotchkote ${ }^{\mathrm{TM}} 345$ and Polyoil ${ }^{\mathrm{TM}}$ based-coating showed good resistance to SCCO2.

4. High thickness was good for substrate protection. However, it was not for SCCO2 resistance, due to its vulnerable blister formation. Thickness was important for different coating preparation for SCCO2 transportation.

Noteworthy advancements in the design of new organic coatings can be using Polyoil ${ }^{\mathrm{TM}}$ 130 based coatings. Polyoil ${ }^{\text {TM }} 130$ based coatings showed a good resistance to SCCO2 at both high temperature and high pressure and low temperature and low pressure. With exposure to SCCO2, weight and thickness of coatings did not change significantly, which proved that designed organic coating did not dissolve in SCCO2 and did not absolve SCCO2 either. Visual results showed no blister formation, which proved that Polyoil ${ }^{\mathrm{TM}} 130$-based coatings had a high 
adhesion with steel substrate, and did not allow much diffusion of SCCO2 in the coatings. Electrochemical impedance measurement showed that coatings could protect steel substrate. All these results proved Polyoil ${ }^{\mathrm{TM}}$ 130-based coatings could be serving a potential candidate for internal coatings to transport SCCO2.

In conclusion, a commercial coating $3 \mathrm{M}$ Scotchkote ${ }^{\mathrm{TM}} 345$ coating and a designed Polyoil ${ }^{\mathrm{TM}}$ 130-based coatings could be used as internal coatings to transport SCCO2 with thickness above $50 \mu \mathrm{m}$. These two coatings could extend the service life of pipeline for SCCO2 transportation to save economic cost as well as human life. 


\section{Introduction}

Carbon dioxide is one of the greenhouse gases, and its steadily increasing concentration in the atmosphere is a cause of societal concern. To control and begin decreasing this concentration, one method under examination is the sequestration of carbon dioxide by geological storage. The transportation of $\mathrm{CO}_{2}$ from its point source to the geological sequestration site, thus, is very important for such a process. The best way yet determined for such transport is to move it as SCCO2 in pipelines. The design of the pipelines for long-term durability under such use conditions is critical.

$\mathrm{CO}_{2}$ is an acid gas and can react with water to form carbonic acid. Carbonic acid corrosion of carbon steels is recognized as one of the major damages in pipeline steel ${ }^{1}$.

$$
\begin{gathered}
\mathrm{Fe} \rightarrow \mathrm{Fe}^{2+}+2 e \\
\mathrm{H}_{2} \mathrm{CO}_{3}+2 e \rightarrow \mathrm{CO}_{3}^{2-}+\mathrm{H}_{2} \\
\mathrm{Fe}^{2+}+\mathrm{CO}_{3}^{2-} \rightarrow \mathrm{FeCO}_{3}
\end{gathered}
$$

When the $\mathrm{CO}_{2}$ partial pressure is greater than $207 \mathrm{kPa}$, carbonic acid will be produced directly $^{2}$. The concentration of carbonic acid is important for the corrosion behavior. The corrosion rate increases significantly below $\mathrm{pH}$ 3.52. The corrosion in carbonic acid is more severe than $\mathrm{HCl}$ under the same $\mathrm{pH}$ due to the additional cathodic reaction, $\mathrm{H}_{2} \mathrm{CO}_{3}$ reduction in the system ${ }^{3}$. High pressure and high temperature increase the corrosion rate in the case of scale free $\mathrm{CO}_{2}$ corrosion ${ }^{4}$. Drying of $\mathrm{CO}_{2}$ can be regarded as an effective corrosion protection ${ }^{5}$. The corrosion inhibitor monoethylene glycol can be added to prevent the corrosion reactions4. It has been proved than $20 \mathrm{ppm} \mathrm{CO}_{2}$ corrosion inhibitor can decrease the corrosion rate to $0.1 \mathrm{~mm} / \mathrm{year}$ at temperature around $30^{\circ} \mathrm{C}$ and pressure around $72 \mathrm{bar}$. The formations of protective iron carbonate layers will change the kinetics of process ${ }^{6}$. It serves as a diffusion barrier and covers a portion of the steel surface. Iron carbonate scale growth and its protectiveness depend primarily on the precipitation rate. The protection only occurs when the precipitation rate is higher than the corrosion rate. The higher temperature results in a higher precipitation rate, which can form a protective layer6. The corrosion mechanism can be shown in Figure 1. It could be found that $\mathrm{Fe}_{3} \mathrm{C}$ serves as the cathodic site, while the $\mathrm{FeCO}_{3}$ layer serves as the protective layer. $\mathrm{H}_{2} \mathrm{~S}$ can cause severe corrosion along with SCCO 2 even at concentrations below $1 \mathrm{ppm}^{7}$. Iron sulfide can be formed as the corrosion product. Corrosion cracking may also happen due to the sulphide 
stress $^{8}$. HAc (acetic acid) can affect the protective layer of iron carbonate. At 500ppm HAc, the layer becomes porous. At 2000ppm HAc, the layer disappears ${ }^{9}$.
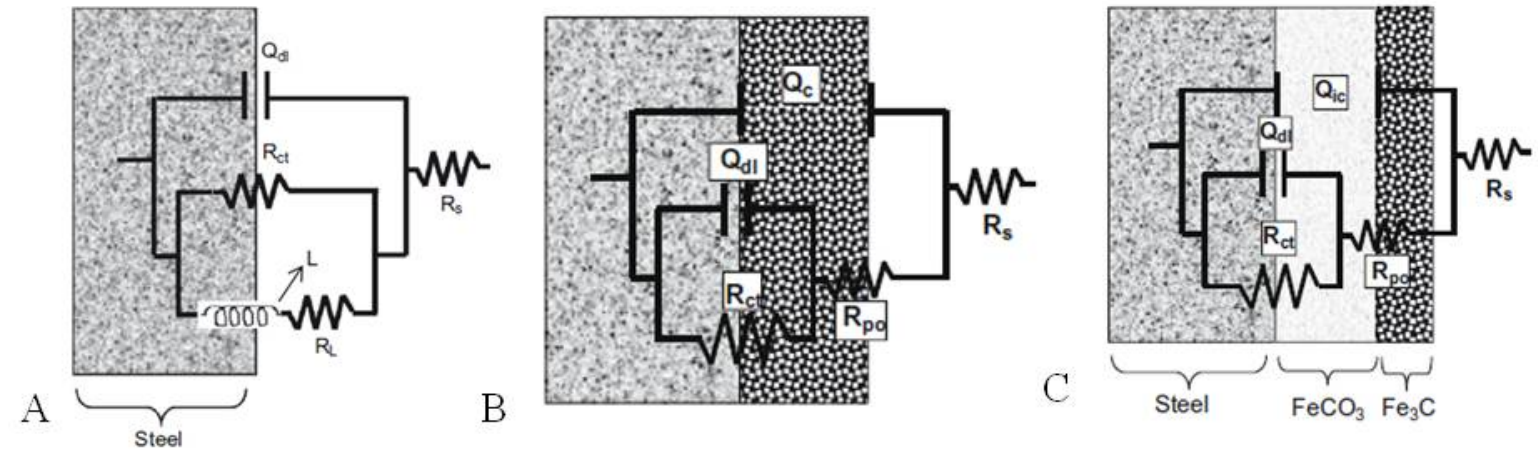

Figure 1. The sweet corrosion mechanism of steel ${ }^{10}$. Farelas F et al., Corrosion Science,

$$
\text { 52(2010), 509-517 }
$$

Steel pipeline can be designed with zinc plating, coating, and plastic lining ${ }^{11}$. The cathodic protection can be used by adding metal particles in the polymer matrix. To maximum the protection and to act as the barrier properties, impregnation of metal into polymer substrate would be a better application ${ }^{12}$. Using a pigment to entrap $\mathrm{CO}_{2}$ was described ${ }^{13}$ as a way to sequestrate traces of $\mathrm{CO}_{2}$.

The recent NACE 2011 Conference \& Expo presented several papers ${ }^{14,15,16,17,18,19}$ about the corrosion research for dirty-SCCO2. They all considered the water effect on the corrosion of the pipeline steel. Mohd F. Mohamed et al. ${ }^{14}$ made the corrections for the $\mathrm{CO}_{2}$ reactions and the $\mathrm{CO}_{2}$ solubility properties under supercritical conditions, and set up the new models for the mutual solubility. The experimental data were in agreement with the modeling results. The paper also discusses the solubility parameters for $\mathrm{CO}_{2} / \mathrm{H}_{2} \mathrm{O}$ mutual system. Yucheng Zheng et al. not only investigated the corrosion rates for different steels under water/SCCO2 system at different temperatures ${ }^{15}$, but also investigated the corrosion inhibitor effects on the corrosion rates ${ }^{16}$. They found that the corrosion reaction was mainly dependent on the acid reaction, which was related to the carbonic acid concentration and the growth of the corrosion products. They also found that temperatures above $110^{\circ} \mathrm{C}$ would cause severe corrosion. They discovered hexadecylthrimethylammonium bromide produced the best corrosion protection among all the inhibitors tested. However, none was efficient enough to reduce the corrosion rate below $1 \mathrm{~mm} / \mathrm{y}$. The interface gap was also investigated in the paper ${ }^{17}$. The results showed that it only 
increased the corrosion rate at the initial period. With the corrosion scale formation, the interface gap would not be the critical factor to the corrosion rate. Some of them considered more contaminating gases, such as $\mathrm{SO}_{2}$ and $\mathrm{O}_{2}{ }^{18}$, effect on the corrosion of the pipeline steel. They found that a small amount of $\mathrm{SO}_{2}$ could increase the corrosion rate dramatically with the water also included in the impurities. Of all these papers, only one paper ${ }^{19}$ used the electrochemical impedance spectroscopy (EIS) to investigate the corrosion process. It was quite supporting if EIS data is used to examine the corrosion process. These authors found that the passive layer was formed, degraded, and reformed. The pressurization period was important to the following corrosion process. In conclusion, the measurement of the corrosion protection behavior will be primarily utilizing electrochemical impedance spectroscopy to propose corrosion processes and mechanisms.

Corrosion induced damages result into enormous costs. Early identification and monitoring of such corrosion is a key method to avoid damage that might endanger user safety and reduce maintenance costs. A primary way to accomplish this purpose is to characterize corrosions by electrochemical sensors. Electrochemical techniques are used for detections, including half-cell potential technique, linear polarization technique, electrochemical impedance spectroscopy, electrochemical noise methods, and use of electrode arrays. However, few of these methods can be presently applied in field monitoring. Corrosion monitor sensors now available work by measuring corrosion current density to monitor corrosion process, although in a variety of forms, such as tower-type sensor ${ }^{20}$, multi-cell sensor ${ }^{21}$, a two-cell electrochemical impedance sensors $^{22}$, a galvanic sensor ${ }^{23}$, electrochemical impedance sensors and electrochemical noise sensors $^{24,25}$. External materials can be added to monitor structure corrosion ${ }^{26}$. Another way to characterize the corrosion is to use optical fiber sensors to measure spectral changes or intensity changes by Bragg gratings ${ }^{27}$. A fibre Bragg grating (FBG) is a structure with periodic modulation of the refractive index. It is sensitive to strain and temperature. Usually FBG is bonded on the surface and responses with the strain caused by corrosion reaction. During the measurement, peak shift means corrosion, while multiple peaks mean inhomogeneous corrosion27. It also detects wavelength shifts due to interactions with specific ions of corrosion products. The third way to characterize the corrosion is to use sound wave characterization sensors. Ultrasonic transducer can measure thicknesses of structures and to monitor and assess exfoliation corrosion ${ }^{28,29}$. Electromagnetic sensors can be used to detect corrosions due to the 
influence of chemical composition and microstructure by corrosion on magnetic properties of ferromagnetic materials ${ }^{30}$, and can be used for coating defects and disbondment as an in-line inspection method of pipeline coating ${ }^{31}$. The fourth way to characterize the corrosion is to use chemical sensors. Immobilized $\mathrm{pH}$-sensitive fluorescent dye can also be used to detect sites of corrosion $^{32}$. However, all the sensors are used until that corrosion happens significantly. For coated pipeline to transport supercritical carbon dioxide, corrosion happens only if dirty $\mathrm{SCCO} 2$ can diffuse into coatings. A chemical sensor could be embedded in coatings to detect the concentration of dirty $\mathrm{SCCO} 2$. A novel planar optical sensor to monitor carbon dioxide and $\mathrm{pH}$ simultaneously ${ }^{33}$ may be a good candidate, because water is the most common component of dirty $\mathrm{SCCO} 2$ and corrosion would not happen until $\mathrm{pH}$ is below $3.0^{34}$. A multi sensor system ${ }^{35}$ for different gases could be another candidate for $\mathrm{H}_{2} \mathrm{~S}, \mathrm{NO}_{2}, \mathrm{SO}_{2}$, and so on.

Exterior conditions with $\mathrm{SCCO} 2$ will be similar to pipelines already in United States handling warm fluids. Investigations including potential temperature effect and soil condition effect have already been done. Actual pipelines of alloys chosen for $\mathrm{SCCO} 2$ transportation will need study. However, no new research will be needed.

This project is mainly to develop the protective coatings for co-sequestration processes and pipelines. Some experimental work was performed to examine the function of existing coating systems to $\mathrm{SCCO} 2$ exposure will be conducted. The polymers suitable to use in coatings were designed to be $\mathrm{SCCO} 2$ resistant. The major part of our efforts is geared towards establishing the corrosion mechanisms under the testing conditions and the new coatings as the protective coatings. In the meantime, corrosion monitoring sensors are proposed to be built to early identify corrosion reactions on pipeline to transport SCCO2. However, field exposure or expanded lab exposure is needed to verify results under actual pipeline conditions.

\section{Experiments}

Supercritical carbon dioxide was generated using the set-up presented in Figures 2 and 3. The coated sample panels will be put into the high pressure test vessel. The vessel was immersed in a water bath at approximately $4^{\circ} \mathrm{C}$. The vessel was vacuumed first and then filled with carbon dioxide gas. The process was repeated three times to ensure there was no contamination with another gas. After this the vessel was filled with around $1 \mathrm{lb}$ of carbon dioxide (the $\mathrm{CO}_{2}$ tank was placed on a scale to monitor the weight), with the pressure set to approximately $1000 \mathrm{psi}$. With the system tightly sealed, the water bath started to rise temperature to the preset temperature. 
Care was taken to adjust the ventilated valve to release the pressure when the pressure was over 1800 psi. After adjustments, a predefined pressure was obtained and the sample was held under those conditions for different periods.

Steel panels (S36) were used as the substrate in the following coating process. For the spray process, the panels were sandblasted first and degreased by hexane. For the drawdown process, the panels were sanded using \#320 and \#600 sand papers and degreased by acetone. Teflon $^{\mathrm{TM}}$ panels were used as the substrate in the following film formation process. Teflon ${ }^{\mathrm{TM}}$ panels were degreased by hexane before the spray process.

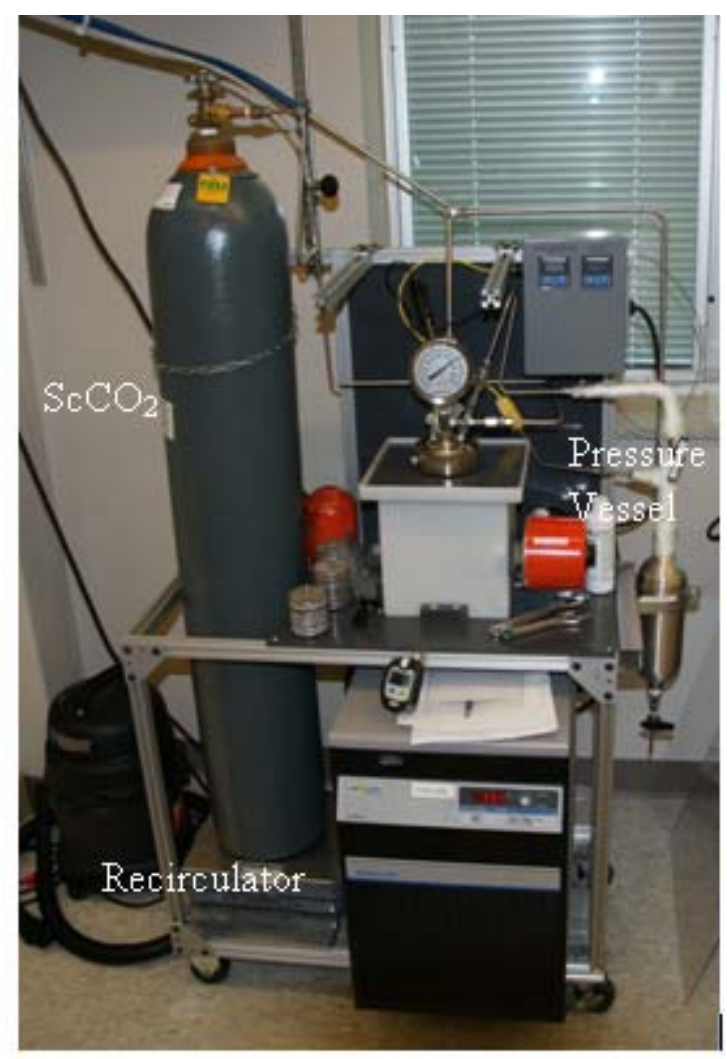

Figure 2. Complete reaction set-up 

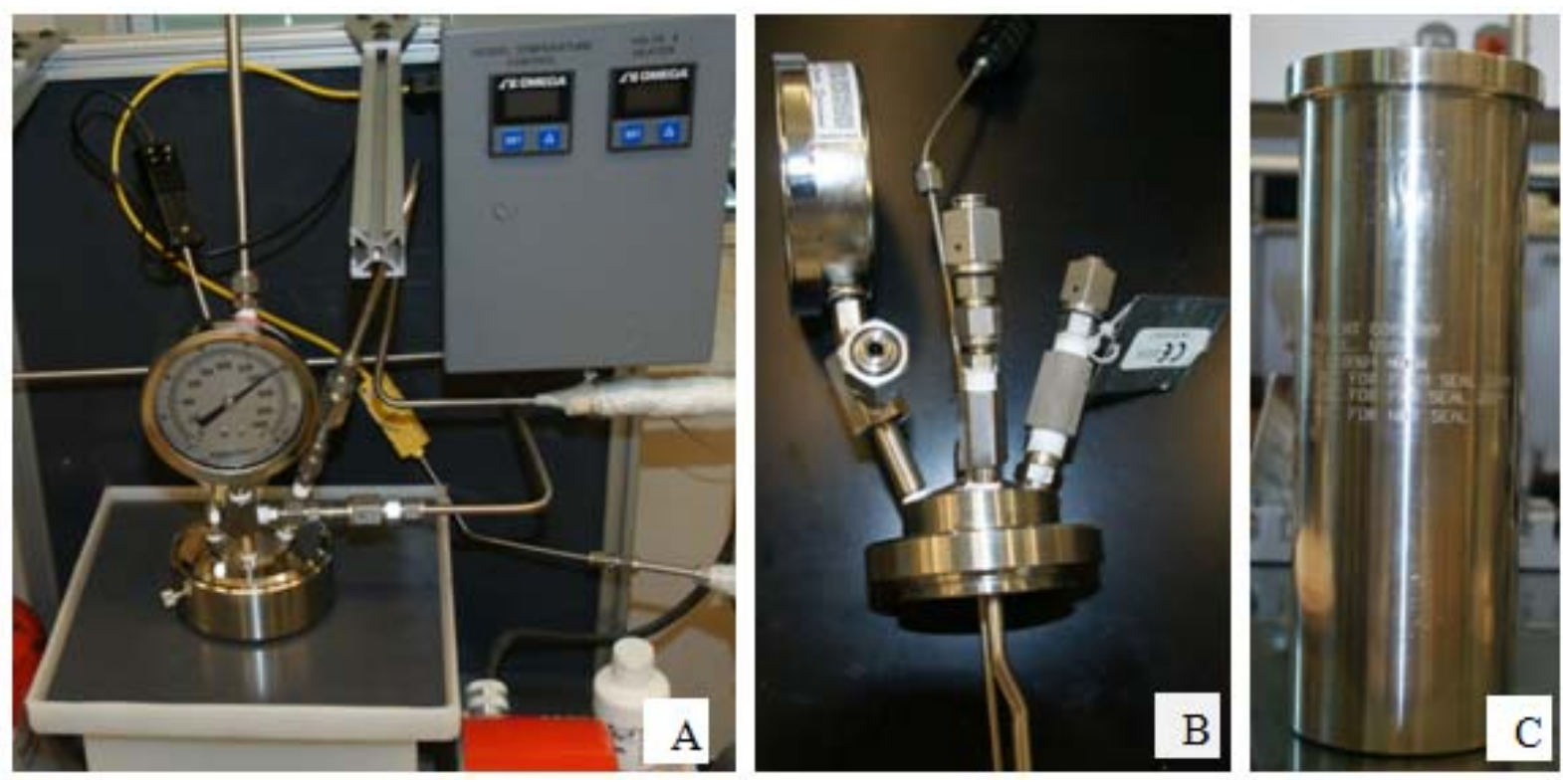

Figure 3. The parts of the reaction set up. A-the assembled vessel. B-the top part of the vessel and $\mathrm{C}$-the bottom part of the vessel.

In order to design protective coatings for supercritical carbon dioxide (SCCO2) transportation, coatings must be resistant to SCCO2. Due to high solvency of SCCO2, it can dissolve many polymers. There are three mechanisms regarding the solubility ${ }^{36}$. The first is the electron donor-acceptor mechanism. The second is the specific interaction, such as the SCCO2 and polymer dipoles. The third is the electrostatic interactions, such as the SCCO2 and polymer $\pi$ systems. Research has shown that intermolecular interactions between polymer segments and $\mathrm{SCCO} 2$ are much more responsible for miscibility than hydrostatic pressure ${ }^{36}$. Carbonyl or ether groups that are either in the backbone or on side chains can specifically interact with SCCO2. Polymers that are often difficult to dissolve in other fluids such as fluorine-substituted polymers and silicon based polymers are dissolved in the SCCO2, this being especially true for perfluoroalkyl ethers and acrylates ${ }^{36}$. The solvency of SCCO2 increases with the increasing content of polar groups in the polymer, due to the increased polarity of SCCO2 vs the subcritical fluid ${ }^{36}$. However, hydroxyl end groups decrease polymer solubility ${ }^{37}$. The solvency of $\mathrm{CO}_{2}$ in general increases with the pressure ${ }^{38}$. Polymer chain entanglement confined free volume will restrict a limit for the solvency of $\mathrm{SCCO} 2^{39}$. Chain flexibility aids dissolution. High crystalline polymers have a low solubility due to the regular structure and much slower transport processes $^{36}$. For the semicrystalline polymers, the solubility occurs mainly in the amorphous 
regions. Polymers of molecular weight higher than $20000 \mathrm{~g} / \mathrm{mol}$ will have a negligible solubility. Literature review for the potential candidate for $\mathrm{SCCO} 2$ resistant polymers is given in Table 1.

In conclusion, high crystallinity, restricted molecular mobility, high crosslinking and high dipole structure would be beneficial in polymers for $\mathrm{SCCO} 2$ resistance $^{40}$. The presence of carboxylic acid groups in the polymer backbone ${ }^{41,42}$ would be beneficial for $\mathrm{SCCO} 2$ resistance, although not good for the water resistance. Highly restriction polymer mobility with higher glass transition temperature will also provide $\mathrm{SCCO} 2$ resistance.

Table 1. Potential candidate for $\mathrm{SCCO} 2$ resistant polymer

\begin{tabular}{|c|c|c|c|c|}
\hline Polymer & $\begin{array}{c}\text { Experimental } \\
\text { conditions }\end{array}$ & $\begin{array}{c}\text { Visual sampling } \\
\text { due to exposure } \\
\text { to SCCO2 }\end{array}$ & $\begin{array}{c}\text { Polymer property } \\
\text { related to SCCO2 } \\
\text { resistance }\end{array}$ & Reference \\
\hline Poly(vinyl chloride) & $\begin{array}{c}2000 / 3000 \mathrm{psi}, \\
40 / 70^{\circ} \mathrm{C}\end{array}$ & $\begin{array}{c}\text { A light } \\
\text { dissolution }\end{array}$ & High dipole C-Cl & 40 \\
\hline $\begin{array}{c}\text { Polypropylene } \\
\text { Polyethylene, } \\
\text { Teflon }\end{array}$ & $\begin{array}{c}2000 / 3000 \mathrm{psi}, \\
40 / 70^{\circ} \mathrm{C}\end{array}$ & A light yellow & High crystallinity & 40 \\
\hline $\begin{array}{c}\text { Nylon } 66 \\
\text { Copolymer with } \\
\text { poly(methacrylic acid) }\end{array}$ & $\begin{array}{c}2000 / 3000 \mathrm{psi}, \\
40 / 70^{\circ} \mathrm{C}\end{array}$ & Some bubbles & High crystallinity & 40 \\
\hline $\begin{array}{c}\text { High branched phenol } \\
\text { Surface modified } \\
\text { polystyrene by } \\
\text { carboxylic acid group }\end{array}$ & $\begin{array}{r}1232-2857 \mathrm{psi}, \\
40-60^{\circ} \mathrm{C}\end{array}$ & SCCO2 resistant & Static repulsion & 42 \\
\hline $\begin{array}{c}\text { Higher fraction of hard } \\
\text { segment of } \\
\text { poly(urethane) }\end{array}$ & $\begin{array}{c}1000-3000 \mathrm{psi}, \\
42^{\circ} \mathrm{C}\end{array}$ & Low sorption of \\
SCCO2 & High restriction & 43 \\
\hline
\end{tabular}

The coating materials that we identified for initial evaluation were commercial pipeline and specialty coatings. The characterization was mainly of barrier properties under supercritical 
conditions of commercial coating systems, TZ ${ }^{\mathrm{TM}} 904$ coating, DevChem ${ }^{\mathrm{TM}} 253$ coating, Scotchkote ${ }^{\mathrm{TM}} 345$ coating, and Scotchkote ${ }^{\mathrm{TM}} 323$ coating. These coatings were identified based on the findings from literature review and consultation with technical service personnel at the respective companies from which they were procured. TZ ${ }^{\mathrm{TM}} 904$ is a performance coating from Chevron Phillips Chemical Company and is a high-build modified epoxy coating engineered to provide outstanding resistance for steel structures in corrosive environments (http://www.cpchem.com/bl/specchem/en-us/tdslibrary/TZ_904_TDS_v808.pdf). Devchem ${ }^{\text {TM }}$ 253 is a two-component epoxy novolac coating from International Paints (http://www.duspec.com/DuSpec2/product/ProductDocumentSearchController.htm?documentFo rmat $=$ pdf\&systemSetId=13\&productCode=253\&document Type $=$ datasheet\&submit $=$ Get + Docu ment). DevChem ${ }^{\mathrm{TM}} 253$ has an exceptional resistance to a wide range of chemicals and solvents. DevChem $^{\mathrm{TM}} 253$ is typically used for industrial storage and process chemical tanks and pipelines, high pressure crude oil pipes and separation tanks. DevChem ${ }^{\mathrm{TM}} 253$ is also used as a protective coating for highly corrosive environments. Scotchkote 323 is a two-component system designed to protect steel pipe and other metal surfaces from the harsh effects of corrosion and can be used as internal lining (http://multimedia.3m.com/mws/mediawebserver?mwsId= SSSSSu7zK1fs1 xtU4Y_xMYtxev7qe17zHvTSevTSeSSSSSS--). This coating is resistant to damage by acids and bases in the $\mathrm{pH}$ range of 2 to 14 . Scotchkote ${ }^{\mathrm{TM}} 323$ is also resistant to hydrocarbons and many solvents. Scotchkote ${ }^{\mathrm{TM}} 345$ is a liquid one-part phenolic primer designed for application to metal surfaces prior to topcoating with Scotchkote fusion bonded epoxy (FBEwhich is high temperature applied expoxy powder coatings, the current industry standard for the protective layers closest to the metal.) coating (http://solutions.3m.com/wps/portal/3M/en_US/ Corrosion/Protection/Products/Catalog2/?PC_7_RJH9U523001R40I49E2FVI20E3_nid=L7QJ75 BXFQbe7C5QZ78847gl). The complete coating system is expected to provide excellent resistance to $\mathrm{CO}_{2}, \mathrm{H}_{2} \mathrm{~S}, \mathrm{CH}_{4}$, petroleum distillates and brine at elevated temperatures and pressures.

The specialty coatings we have examined are crosslinked liquid natural rubbers (Figure 4). The structure is aliphatic without any $\mathrm{CO}_{2}$-philic sides. It is also hydrophobic. With crosslinking, this polymer should become more $\mathrm{CO}_{2}$-resistant and water-resistant, and increase its strength, functions important to coating matrix candidate. In addition, liquid natural rubber is inexpensive and relatively easy to process. An organic peroxide compound, such as dicumyl 
peroxide, could crosslink the free double bond in the liquid natural rubber. This is described extensively in the literature on rubber compounding for commercial and tire use. The sulfurcrosslinking of natural rubber, as usually used for tires, can be swollen in $\mathrm{SCCO} 2$ with crosslinking density around $10^{7} \mathrm{~mol} \mathrm{~L}^{-144}$. With the organic peroxide compound used for the crosslinking reaction, the shorter chain length between crosslinked branchs than the sulfur will make the rubber less elastic, which will be better for $\mathrm{SCCO} 2$ resistance ${ }^{45}$.

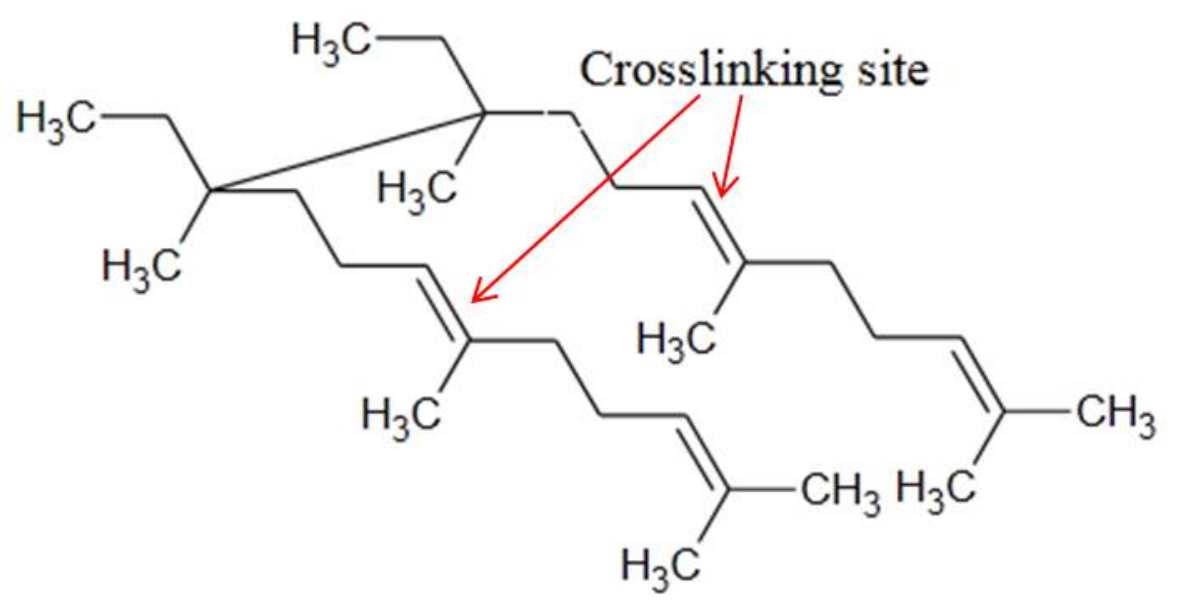

Figure 4. The molecular structure of the crosslinked natural rubber

Polybutadiene, an aliphatic polymer and crosslinkable, can serve as a SCCO2 resistant polymer as well as a good barrier polymer. The crosslinking process will increase the cohesive strength, which should increase $\mathrm{SCCO} 2$ resistance. The liquid polybutadiene can be crosslinked by both sulfur and peroxide, such as dicumyl peroxide. The difference between the two processes is the covalent bonds in between, where in the sulfur process the covalent bonds are polysulfidiccarbon bonds and in the peroxide process the covalent bonds are carbon-carbon bonds. Higher $\mathrm{Tg}$ can be obtained for the sulfur-crosslinked polybutadiene at the same crosslink density ${ }^{46}$. The polybutadiene rubber can also be crosslinked by exposure to radiation, such as electron beam or ultraviolet radiation ${ }^{47}$. The UV curable formulation needs a photosensitive group present such as an acrylic. However, this could be detrimental to the $\mathrm{SCCO} 2$ resistance property ${ }^{48}$. To make good adhesion to the metal and the primer, which is good for eliminating the blister formation on the coatings caused by the exposure to $\mathrm{SCCO}$, rubber hydrohalide, hydrochloride rubber, or cyclicized rubber are strongly recommended ${ }^{49}$. Polychloroprene is chosen in the formulation, since it could be prepared in-situ, or bought by commercial trade name of "neoprene" ${ }^{49}$. Another 
reason is that polychloroprene can be functionalized in the corrosion preventing coating compositions ${ }^{50,51}$. Based on previous statements, Polyoil ${ }^{\mathrm{TM}}$ 130, a non-hydolysable liquid polybutadiene (http://corporate.evonik.com/en/products/search-products/Pages/productdetails.aspx?pid=22351\&pfcat=5043), was obtained from EVONIK Industries. It is a highly reactive crosslinkable binder. Polychloroprene can be purchased from http://bayermaterialsciencenafta.com/products/index.cfm?mode=grades\&pp_num=EB7C4E4A9321-3303-8B3789A0E86FCC74\& o num=14. The initiator tert-Butyl peroxide was obtained from Sigma-Aldrich. The formulation is shown in Table 2, as well as the controllable parameters shown in Table 3.

Table 2: The formulation of SCCO2 resistant coating

\begin{tabular}{|c|c|c|c|}
\hline \multicolumn{2}{|c|}{ Part A } & \multicolumn{2}{c|}{ Part B } \\
\hline Materials & Functions & Materials & Functions \\
\hline polybutadiene & Primer base & Polychloroprene & Adhesion promoter \\
\hline Tert-Butyl peroxide & Crosslinking agent & Solvent: Xylenes & Viscosity adjustor \\
\hline
\end{tabular}

Table 3: The control variables for the coating preparation

\begin{tabular}{|c|c|}
\hline Variables & Functions \\
\hline Ratio of primer to initiator & The crosslinking density and the reaction speed \\
\hline Ratio of primer to polychloroprene & Adhesion property and mechanical properties \\
\hline Temperature & The reaction speed \\
\hline Time & The crosslinking density \\
\hline Solvent & The reaction speed \\
\hline
\end{tabular}

\section{Performance of $\mathrm{TZ}^{\mathrm{TM}} 904$ in supercritical carbon dioxide}

$\mathrm{TZ}^{\mathrm{TM}} 904$ coating, which is in liquid form, was prepared as per details in Table 4 and applied on the steel panels with drawdown technique and spray technique. Four samples were prepared and named to be TZ-D, TZ-S-L, TZ-S-M, and TZ-S-H. The samples were exposed to $\mathrm{SCCO} 2$ and then visually and electrochemically evaluated. 
Table 4. Film formation of TZ ${ }^{\mathrm{TM}} 904$

\begin{tabular}{|c|c|c|c|c|}
\hline Materials & Volume ratio & $\begin{array}{c}\text { Operation } \\
\text { (Toluene adjusted) }\end{array}$ & $\begin{array}{c}\text { Thickness } \\
(\mu \mathrm{m})\end{array}$ & Curing conditions \\
\hline $\begin{array}{c}\text { TZTM-R }^{\text {TM }} \\
904\end{array}$ & \multirow{4}{*}{$1: 1$} & 8mils drawdown & 107 (TZ-D) & \multirow{4}{*}{$\begin{array}{c}\text { Curing for } 24 \text { hours } \\
\text { at room } \\
\text { temperature }\end{array}$} \\
\hline \multirow{3}{*}{$\begin{array}{c}\mathrm{TZ}^{\mathrm{TM}}-\mathrm{H} \\
904\end{array}$} & & \multirow{3}{*}{ Spray } & 63(TZ-S-L) & \\
\hline & & & 145 (TZ-S-M) & \\
\hline & & & 313 (TZ-S-H) & \\
\hline
\end{tabular}

Pictures of the film before and after exposure to supercritical conditions are given in Figure 5. The changes in film thickness and appearance are outlined in Table 5. The thickness increases may be due that the presence of the bubbles underneath, especially when visible blisters were formed on the surface. Without blister formation, the thickness almost keeps constant to confirm that there is no sorption of carbon dioxide in the coating. The blisters form for TZ-D coating and TZ-S-H coating at $40^{\circ} \mathrm{C}$ and 1450 psi for 24 hours. Compared with other coatings, TZ-D coating has a low adhesion force, which causes SCCO2 to diffuse into the film easily. TZ-S-H coating at $40^{\circ} \mathrm{C}$ and 1450 psi for 24 hours has a high pressure to permeate underneath the coating film, and has an enough thickness not to diffuse out of the coating film when pressure is released. The reason might be that under the lower pressure and the lower temperature, $\mathrm{SCCO} 2$ had a lower diffusivity and a higher viscosity. It was difficult for SCCO2 to diffuse into the coatings. When the experiments were finished, there was not enough SCCO2 underneath the coatings to form blisters. For the thinner coatings at the higher pressure and the higher temperature, the diffusion out of coatings was faster than that of the thicker coatings. There was also not so much SCCO2 underneath the coatings. No blister would form at the situations. For the thicker coatings at the higher pressure and the higher temperature, the diffusion out of coatings was difficult. The SCCO2 trapped in the coatings formed the blisters on the surface. Coating films change into powders due that films are brittle and could not stand for high pressure of $\mathrm{SCCO} 2$. 

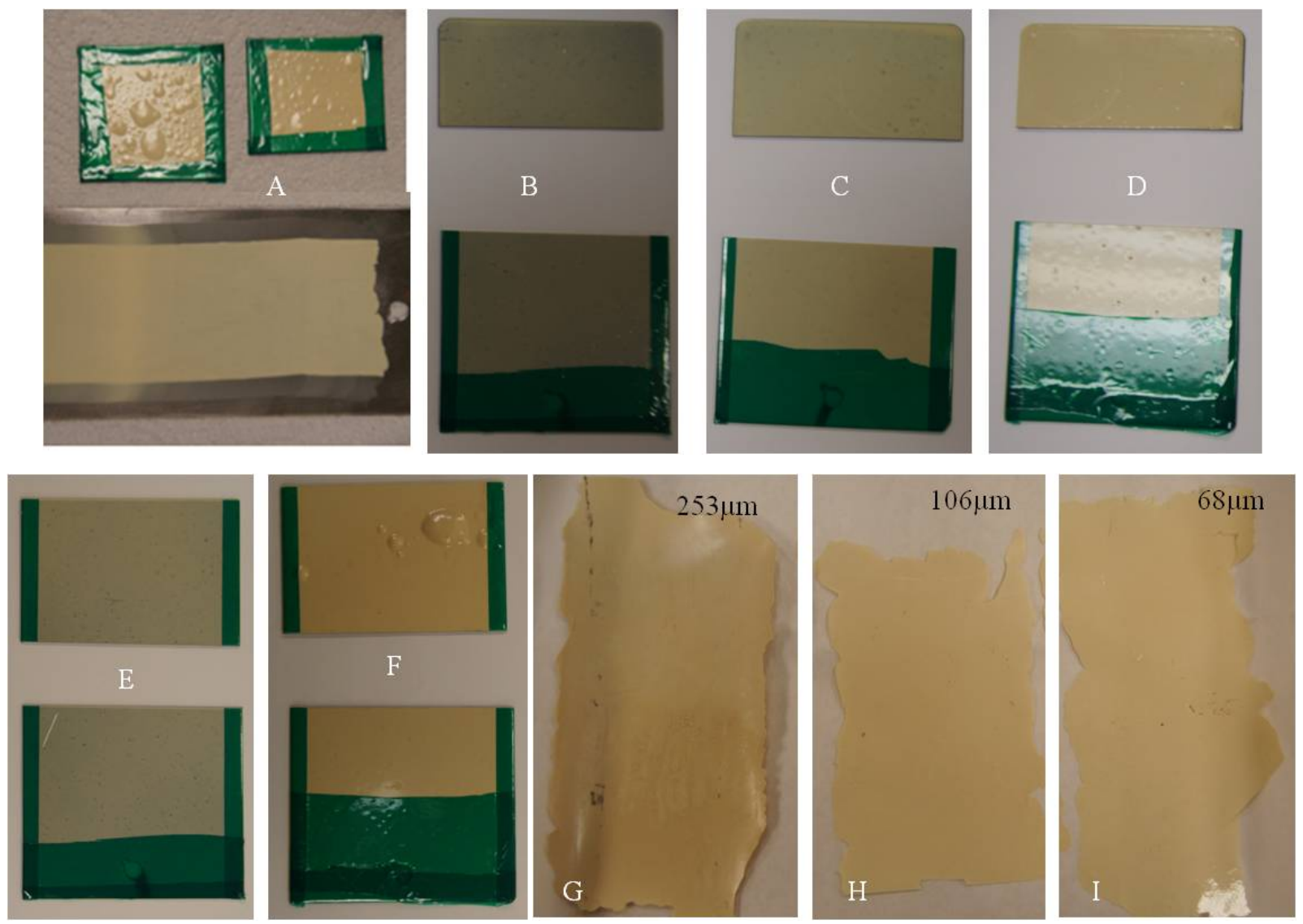

Figure 5. The above- Coated small panels after exposure to $\mathrm{SCCO} 2$ and the below- unexposed original panels. A, TZ-D exposed to SCCO2 of $35^{\circ} \mathrm{C}$ and 1580 psi for 48 hours. B: TZ-S-L, C: TZ-S-M, and D: TZ-S-H exposed to SCCO 2 of $32^{\circ} \mathrm{C}$ and 1100 psi for 24 hours. E: TZ-S-L, and F: TZ-S-H exposed to SCCO2 of $40^{\circ} \mathrm{C}$ and 1450 psi for 24 hours. G, H, I, coating films peeled from Teflon substrate exposed to $32^{\circ} \mathrm{C}$ and 1100 psi for 24 hours. (Note: the samples had to be cut to be able to fit inside the pressure vessel). 
Table 5. Visual characteristics and film thickness differences before and after exposure to supercritical conditions

\begin{tabular}{|c|c|c|c|c|}
\hline Materials & Exposed condition & $\begin{array}{c}\text { Thickness } \\
\text { change } \\
(\mu \mathrm{m})\end{array}$ & $\begin{array}{l}\text { Color } \\
\text { change }\end{array}$ & Appearance change \\
\hline TZ-D & $35^{\circ} \mathrm{C}$ and 1580 psi for 48 hours & $\begin{array}{c}107 \text { to } \\
145\end{array}$ & $\begin{array}{c}\text { No change } \\
\text { yellow }\end{array}$ & $\begin{array}{l}\text { Smooth to blister } \\
\text { underneath }\end{array}$ \\
\hline TZ-S-L & $32^{\circ} \mathrm{C}$ and 1100 psi for 24 hours & 63 to 74 & $\begin{array}{c}\text { No change } \\
\text { light } \\
\text { yellow }\end{array}$ & No change Smooth \\
\hline TZ-S-M & $32^{\circ} \mathrm{C}$ and 1100 psi for 24 hours & $\begin{array}{c}145 \text { to } \\
131\end{array}$ & $\begin{array}{c}\text { No change } \\
\text { Yellow }\end{array}$ & No change Smooth \\
\hline TZ-S-H & $32^{\circ} \mathrm{C}$ and 1100 psi for 24 hours & $\begin{array}{c}313 \text { to } \\
297\end{array}$ & $\begin{array}{l}\text { No change } \\
\text { dark yellow }\end{array}$ & No change smooth \\
\hline TZ-S-L & $40^{\circ} \mathrm{C}$ and 1450 psi for 24 hours & 63 to 80 & $\begin{array}{c}\text { No change } \\
\text { light } \\
\text { yellow }\end{array}$ & No change smooth \\
\hline TZ-S-H & $40^{\circ} \mathrm{C}$ and 1450 psi for 24 hours & $\begin{array}{c}313 \text { to } \\
335\end{array}$ & $\begin{array}{l}\text { No change } \\
\text { dark yellow }\end{array}$ & $\begin{array}{c}\text { Smooth to blister } \\
\text { on the surface }\end{array}$ \\
\hline
\end{tabular}

Electrochemical impedance spectroscopy is shown in Figure 6. For TZ-D sample, the impedance becomes lower after the exposure due to electrolyte penetration. It is in accordance with the blister formation and possibly porous structures. The exposure to SCCO2 has less influence to the impedance of the thicker coatings. At the low frequency, the resistance decreased with the more severe exposure conditions in the SCCO2. With the thicker coatings, the percentage of decrease was smaller. The reason might be the extraction of the coatings to form porous structure in the thinner coatings, but for the thicker coatings, the porous structure was apparently difficult to form. At high frequencies of EIS measurement, the impedance values remained relatively constant through exposure. 

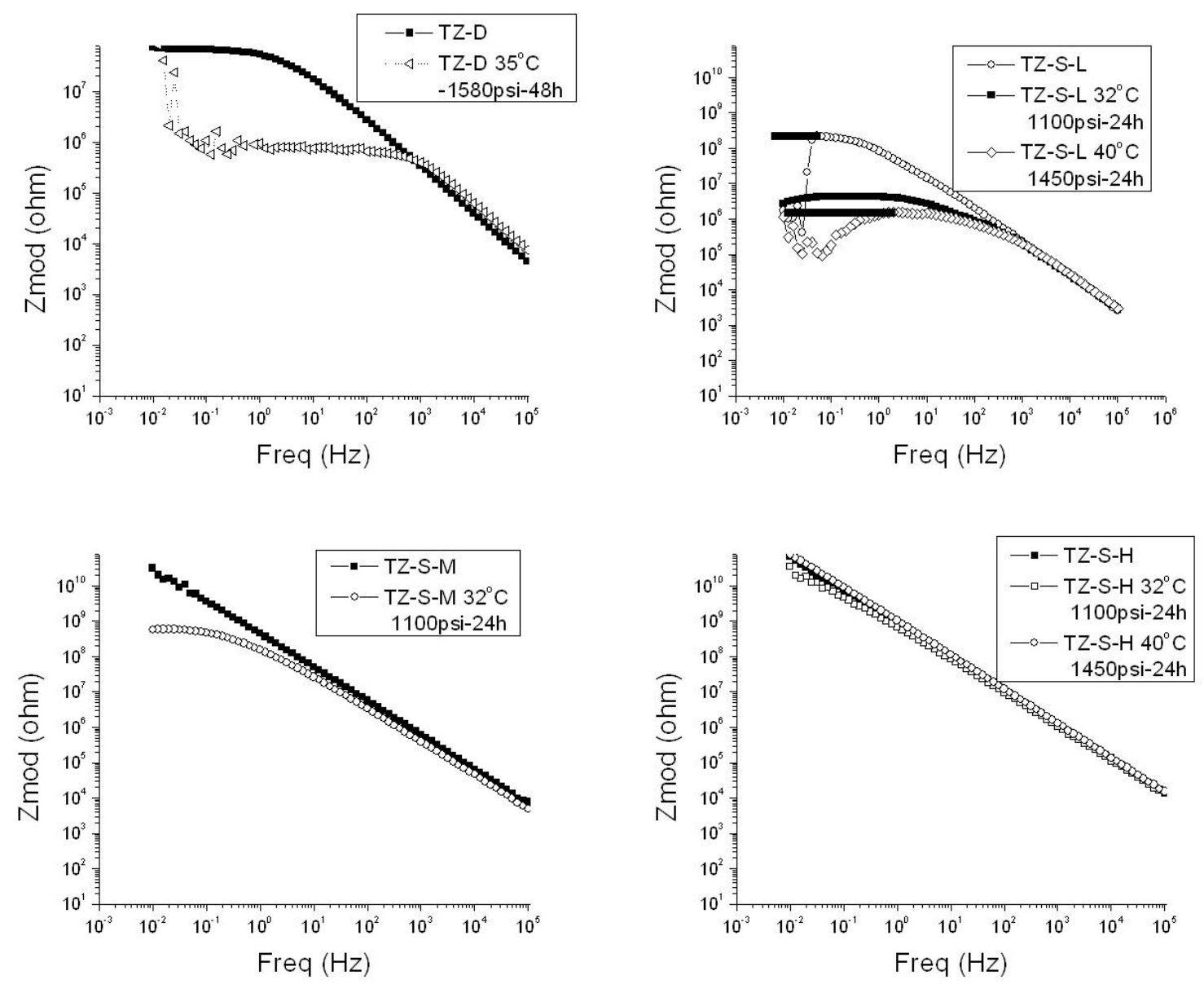

Figure 6. Electrochemical impedance spectroscopy of $\mathrm{TZ}{ }^{\mathrm{TM}} 904$ coatings with various exposure conditions. (The black solid line represents the possible actual spectroscopy)

\section{Performance of DevChem ${ }^{\mathrm{TM}} 253$ in supercritical carbon dioxide}

DevChem $^{\mathrm{TM}} 253$ coating, which is in liquid form, was prepared as per details in Table 6 and applied on the steel panels with drawdown technique and spray technique. Three samples were prepared and named to be DV-D, DV-S-L, and DV-S-H. The samples were exposed to $\mathrm{SCCO} 2$ and then visually and electrochemically evaluated. Pictures of the film before and after exposure to supercritical conditions are given in Figure 7. The changes in film thickness and appearance are outlined in Table 7. 
Table 6. Film formation of DevChem ${ }^{\mathrm{TM}} 253$

\begin{tabular}{|c|c|c|c|c|}
\hline Materials & $\begin{array}{l}\text { Volume } \\
\text { ratio }\end{array}$ & $\begin{array}{l}\text { Operation } \\
\text { (Xylene } \\
\text { adjusted) }\end{array}$ & $\begin{array}{l}\text { Thickness } \\
\qquad(\mu \mathrm{m})\end{array}$ & Curing conditions \\
\hline $\begin{array}{c}\text { DevChem }^{\text {TM }} 253 \\
\text { base }\end{array}$ & \multirow{3}{*}{$4: 1$} & 8mils drawdown & 74 (TZ-D) & \multirow{3}{*}{$\begin{array}{l}\text { Curing for } 5 \text { days at } \\
\text { room temperature }\end{array}$} \\
\hline DevChem $^{\text {TM }} 253$ & & \multirow{2}{*}{ Spray } & 52(TZ-S-L) & \\
\hline convertor & & & 159(TZ-S-H) & \\
\hline
\end{tabular}

Table 7. Visual characteristics and film thickness differences before and after exposure to supercritical conditions

\begin{tabular}{|c|c|c|c|c|}
\hline Materials & Exposed condition & $\begin{array}{c}\text { Thickness } \\
\text { change } \\
(\mu \mathrm{m})\end{array}$ & $\begin{array}{c}\text { Color } \\
\text { change }\end{array}$ & Appearance change \\
\hline DV-D & $35^{\circ} \mathrm{C}$ and 1580 psi for 48 hours & 74 to 79 & $\begin{array}{c}\text { No change } \\
\text { White }\end{array}$ & $\begin{array}{c}\text { Smooth to blister } \\
\text { underneath and } \\
\text { porous structure }\end{array}$ \\
\hline DV-S-L & $32^{\circ} \mathrm{C}$ and 1100 psi for 24 hours & 52 to 58 & $\begin{array}{c}\text { No change } \\
\text { White }\end{array}$ & No change Smooth \\
\hline DV-S-H & $32^{\circ} \mathrm{C}$ and 1100 psi for 24 hours & 159 to & $\begin{array}{c}\text { No change } \\
161\end{array}$ & White \\
\hline DV-S-L & $40^{\circ} \mathrm{C}$ and 1450 psi for 24 hours & 52 to 59 & $\begin{array}{c}\text { No change } \\
\text { White }\end{array}$ & No change smooth \\
\hline DV-S-H & $40^{\circ} \mathrm{C}$ and 1450 psi for 24 hours & $\begin{array}{c}159 \text { to } \\
165\end{array}$ & $\begin{array}{c}\text { No change } \\
\text { White }\end{array}$ & $\begin{array}{c}\text { Smooth to blister } \\
\text { on the surface }\end{array}$ \\
\hline
\end{tabular}



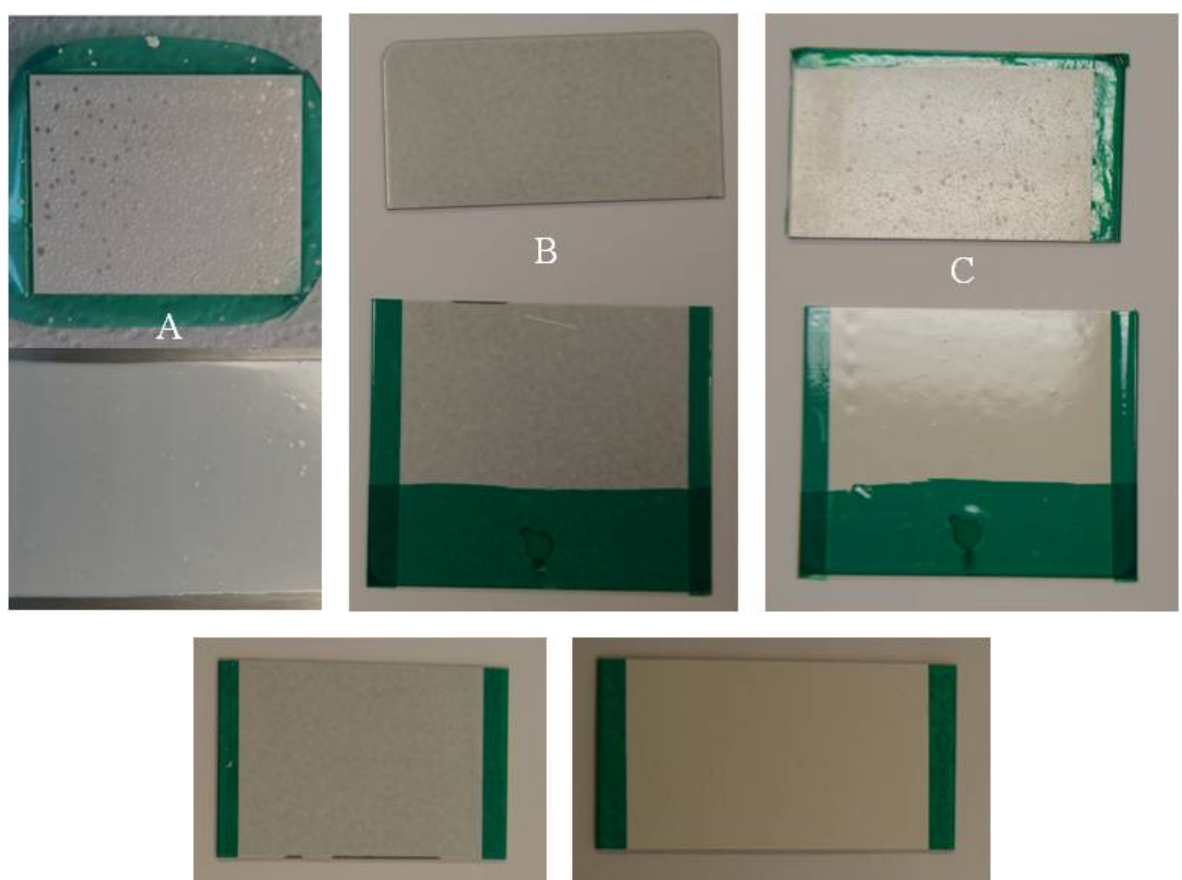

D

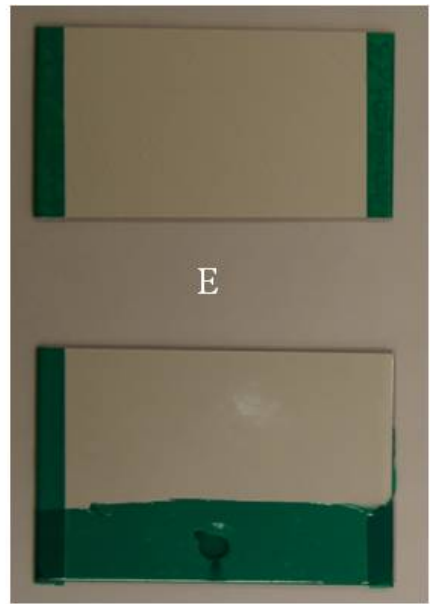

Figure 7. The above- Coated small panels after exposure to $\mathrm{SCCO} 2$ and the below- unexposed original panels. A, DV-D exposed to $\mathrm{SCCO} 2$ of $36^{\circ} \mathrm{C}$ and 1500 psi for 48 hours. B: DV-S-L, and C: DV-S-H exposed to SCCO2 of $32^{\circ} \mathrm{C}$ and 1100 psi for 24 hours. D: DV-S-L, and E: DVS-H exposed to $\mathrm{SCCO} 2$ of $40^{\circ} \mathrm{C}$ and 1450 psi for 24 hours. (Note: the samples had to be cut to be able to fit inside the pressure vessel).

The thickness increases for all sample coatings. Porous structures appear on the surface of DV-D coatings due that the brittleness of the coating causes the bubbles to rupture and thereby form pores on the surface. DV-S-H coatings have blisters on the surface under both low pressure and high pressure. DV-S-L coatings do not have blisters on the surface. The blister forms only in the thicker film.

Electrochemical impedance spectroscopy is shown in Figure 8. At low frequency, the resistance decreased, while at high frequence, the resistance stayed the same. The impedance trends were the same with the impedance trends of $\mathrm{TZ}^{\mathrm{TM}} 904$ coatings. However, there was unusal behavior of DevChem ${ }^{\mathrm{TM}} 253$ coatings exposed to higher temperature and higher pressure. 
The resistance was higher even than the original coatings. The reason might be the contribution of the underneath $\mathrm{CO}_{2}$ or the contribution of the corrosion product such as iron carbonate. It was due to high diffusion of $\mathrm{SCCO} 2$ in DevChem ${ }^{\mathrm{TM}} 253$ coatings. The diffusion control mechanism could also be found in Nyquist plot, while the diffusion control mechanism could not be found for TZ ${ }^{\mathrm{TM}} 904$ coatings. DV-D samples have porous structure on the surface, which yield high error results for our type of EIS test.
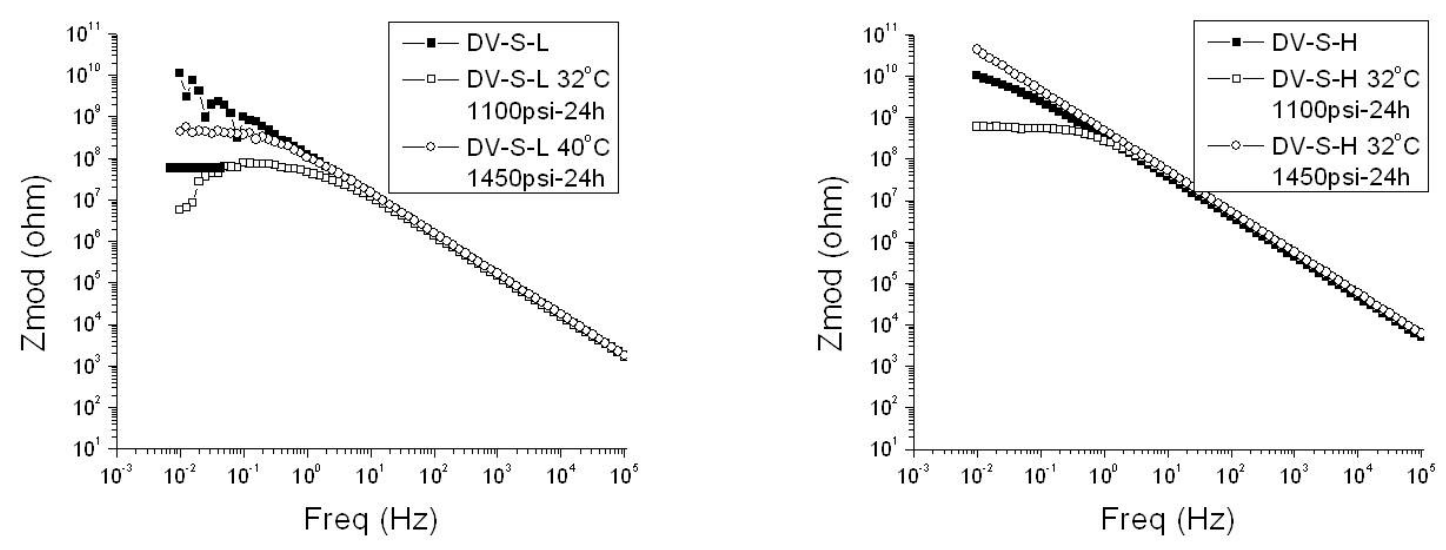

Figure 8. Electrochemical impedance spectroscopy of DevChem ${ }^{\mathrm{TM}} 253$ coatings with various exposure conditions.

\section{Performance of Scotchkote ${ }^{\mathrm{TM}} 323$ in supercritical carbon dioxide}

Scotchkote $^{\mathrm{TM}} 323$ (S323) coating, which is in liquid form, was prepared as per details in Table 8 and sprayed on the steel panels. Two components S323 base and S323 hardener were mixed together 30 minutes before the spray, while xylenes were used to adjust the viscosity of the mixture. Three samples were prepared and named to be S323-S-L, S323-S-M, and S323-S-H. The samples were exposed to $\mathrm{SCCO} 2$ and then visually and electrochemically evaluated. Pictures of the film before and after exposure to supercritical conditions are given in Figure 9. Changes in film thickness and weight are outlined in Figure 10. 
Table 8. Film formation of S323

\begin{tabular}{|c|c|c|c|c|}
\hline Materials & $\begin{array}{c}\text { Volume } \\
\text { ratio }\end{array}$ & $\begin{array}{c}\text { Operation (Xylene } \\
\text { adjusted })\end{array}$ & Thickness $(\mu \mathrm{m})$ & Curing conditions \\
\cline { 1 - 1 } S323 part A & \multirow{2}{*}{$2: 1$} & Spray & $65(\mathrm{~S} 323-\mathrm{S}-\mathrm{M})$ & $\begin{array}{c}\text { Curing for 24hours } \\
\text { at room } \\
\text { S323 part B }\end{array}$ \\
& & & $172(\mathrm{~S} 323-\mathrm{S}-\mathrm{H})$ & temperature \\
\hline
\end{tabular}
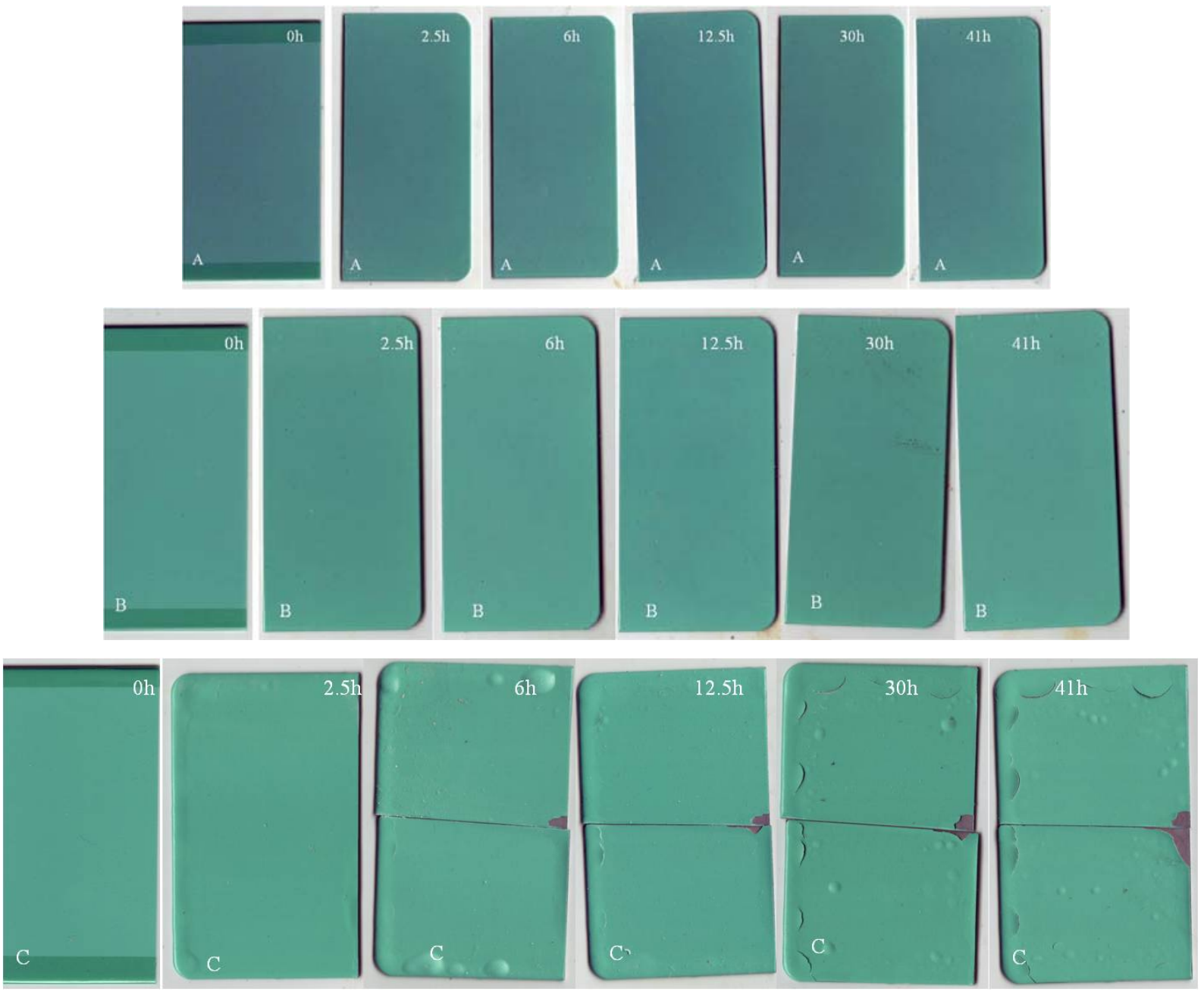

Figure 9. Coated panels with different exposure time to $\mathrm{SCCO} 2$ of $32^{\circ} \mathrm{C}$ and 1100 psi for 24 hours. A, S323-S-L, B, S323-S-M, and C, S323-S-H. 

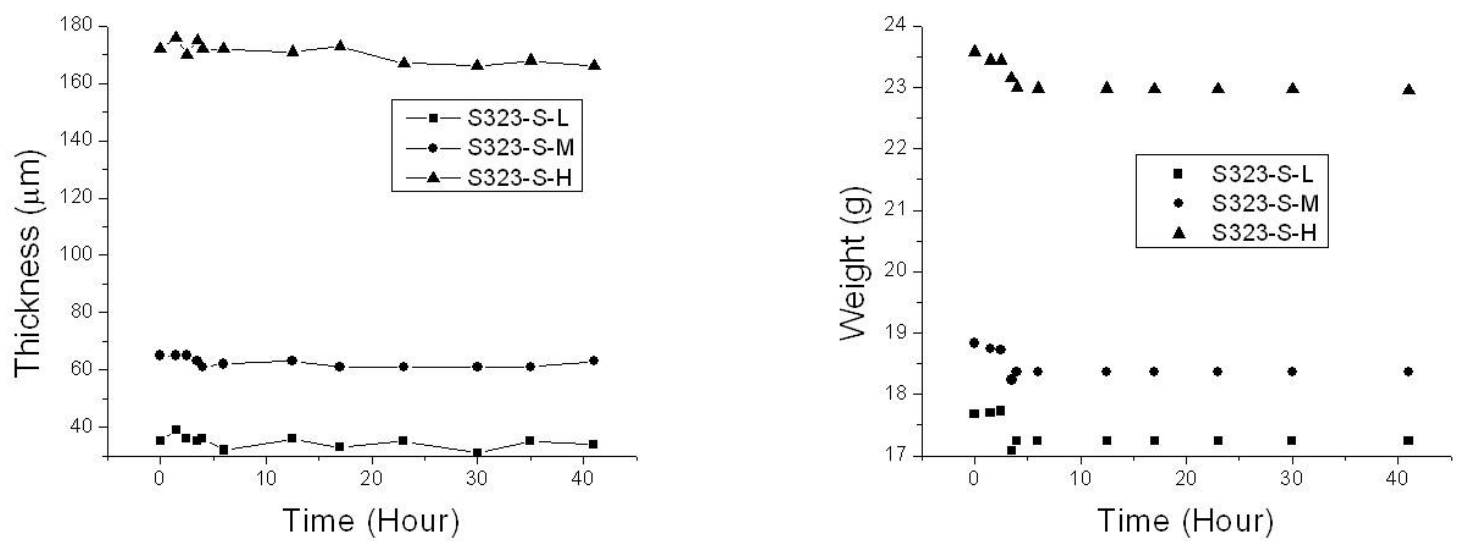

Figure 10. Thickness and weight change due to different periods of exposure.

There was not much difference for different periods of exposure for each thickness coating. However, on the surface of the thickest coatings S323-S-H in Figure 9 C, there appeared the blisters formation, which was in accordance with the previous experiments. The blisters happened on the surface of thickest coatings. However, there was an interesting phenomenon. The number of blisters did not increase with the time of the exposure increasing. With the exposure time increasing, the blister collapsed to be a porous structure. Film thickness and weight did not change significantly.

Electrochemical impedance spectroscopy is shown in Figure 11. The sample S323-S-L continued deteriorating with the exposure of time. The sample S323-S-M had a good barrier property until the exposure time of 41 hour. The sample S323-S-H had a good barrier property until the exposure time of 12.5 hour. 

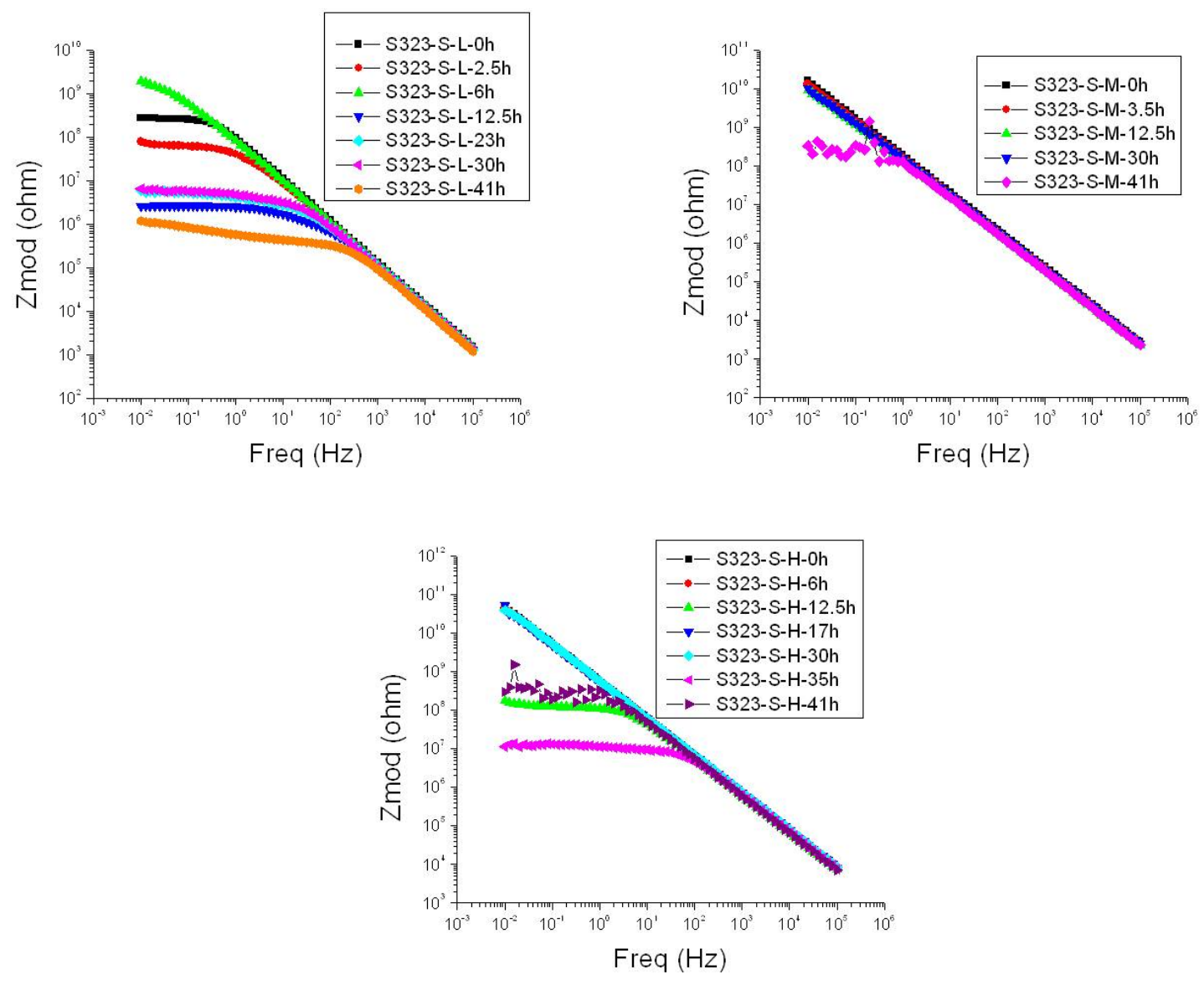

Figure 11. Electrochemical impedance spectroscopy of S323 coatings with various exposure periods in $\mathrm{SCCO} 2$ of $32^{\circ} \mathrm{C}$ and 1100 psi .

\section{Performance of Scotchkote ${ }^{\mathrm{TM}} 345$ in supercritical carbon dioxide}

Scotchkote ${ }^{\mathrm{TM}} 345$ (S345) coating, which is in liquid form, was prepared as per details in Table 9 and sprayed on the steel panels. Three samples were prepared and named to be S345-SL, S345-S-M, and S345-S-H. The samples were exposed to SCCO2 and then visually and electrochemically evaluated. Pictures of the film before and after exposure to supercritical conditions are given in Figure 12. The changes in film thickness and weight are outlined in Figure 13. There is almost no change during the exposure for any of the coatings independent of thickness. Thickness and weight remained constant, which indicated that the coatings were neither imbibing $\mathrm{CO} 2$ nor dissolving $\mathrm{CO} 2$. 

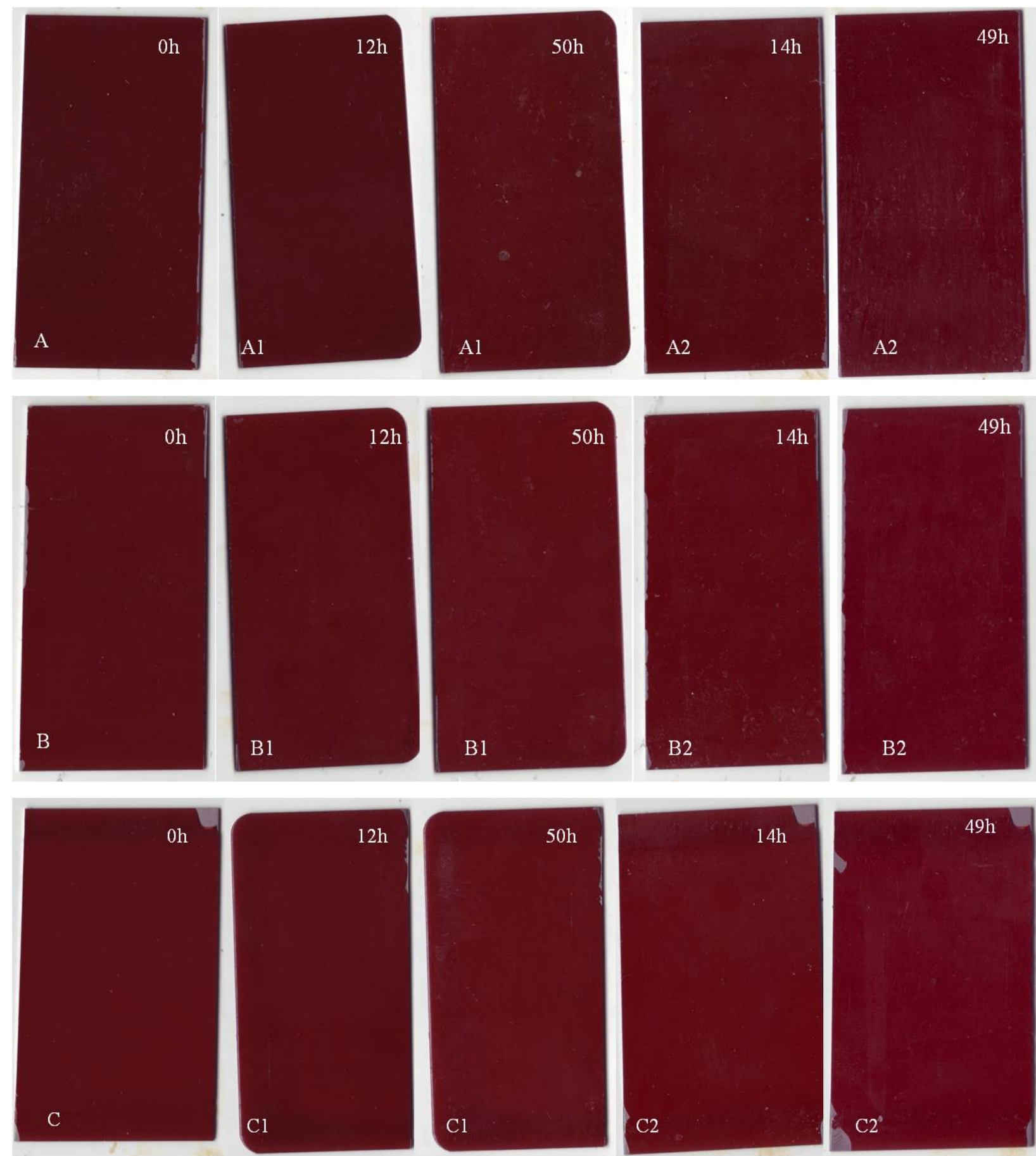

Figure 12. Coated panels with different exposure time to SCCO2. A, S345-S-L, B, S345-S-M, and C, S345-S-H. Numbers after the sample sign are exposure conditions, while 1 represents $32^{\circ} \mathrm{C}$ and $1100 \mathrm{psi}$, and 2 represents $40^{\circ} \mathrm{C}$ and $1450 \mathrm{psi}$. 
Table 9. Film formation of S345

\begin{tabular}{|c|c|c|c|}
\hline Materials & $\begin{array}{c}\text { Operation } \\
\text { (Xylene adjusted) }\end{array}$ & Thickness $(\mu \mathrm{m})$ & Curing conditions \\
\hline \multirow{3}{*}{ S345 } & \multirow{3}{*}{ Spray } & 15 (S345-S-L) & \multirow{3}{*}{$\begin{array}{c}\text { Curing for } 30 \text { minutes } \\
\text { at } 240^{\circ} \mathrm{C}\end{array}$} \\
\hline & & $50(\mathrm{~S} 345-\mathrm{S}-\mathrm{M})$ & \\
\hline & & $180(\mathrm{~S} 345-\mathrm{S}-\mathrm{H})$ & \\
\hline
\end{tabular}
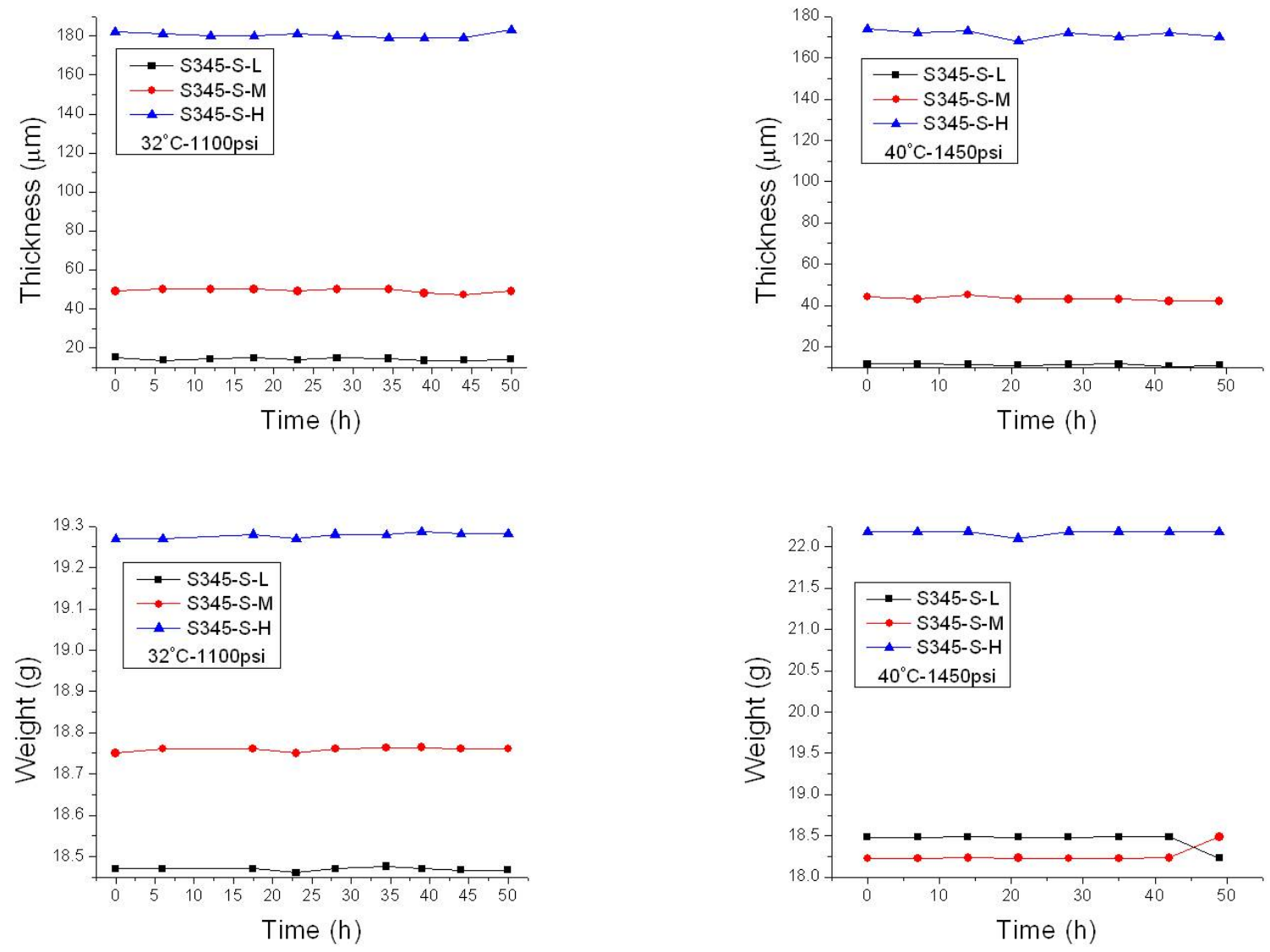

Figure 13. Thickness and weight change due to different periods of exposure Electrochemical impedance spectroscopy is shown in Figure 14. The thinnest film show some decreased impedance with time of exposure. The thickest film did not change. The medium thick film did not change until the long time of exposure of around 50 hours with both conditions of $32^{\circ} \mathrm{C}$ and $1100 \mathrm{psi}$ and $40^{\circ} \mathrm{C}$ and $1450 \mathrm{psi}$. S345 coatings showed a good resistance to 
SCCO2, and thus could serve a good candidate for the SCCO2 resistant coating systems with the coating thickness greater than $50 \mu \mathrm{m}$.
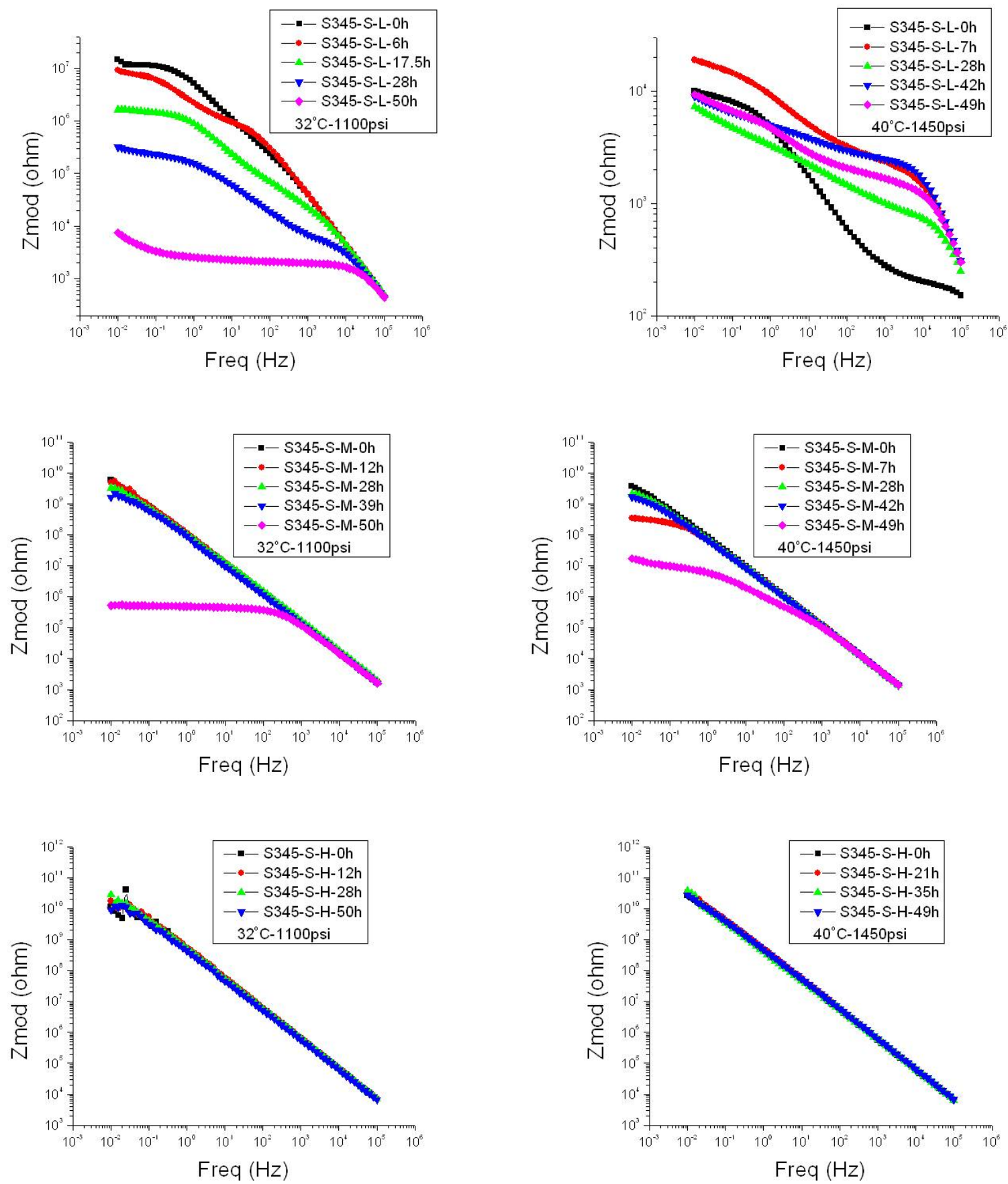

Figure 14. Electrochemical impedance spectroscopy of S345 coatings with various exposure periods. 


\section{Performance of designed polymers in supercritical carbon dioxide}

Designed polymer coatings, which is in liquid form, were prepared with different formulations in Table 10 and were sprayed on the steel panels. Eight formulations with twenty samples were prepared. The samples were exposed to $\mathrm{SCCO} 2$ and then visually and electrochemically evaluated. Pictures of the film before and after exposure to supercritical conditions are given in Figure 15.

For PO-2 and PO-6 samples, the coatings were cured at a lower temperature of $100^{\circ} \mathrm{C}$. The round spots on the surface of the panels were under the Dilute Harrison's Solution (DHS), which was used for our EIS testing. Except these round spots, the panels did not show much difference with the unexposed ones with the exposure to $\mathrm{SCCO} 2$ of $32^{\circ} \mathrm{C}$ and $1100 \mathrm{psi}$. However, with the exposure to $\mathrm{SCCO} 2$ at a higher temperature and a higher pressure of $40^{\circ} \mathrm{C}$ and $1450 p s i$, blisters happened on the surface of coatings, where PO-2 sample had more blisters than PO-6 sample due to lower crosslinking density. For higher temperature cured samples, no blister could be detected on the surface. PO-2-C-M and PB-6-C15-M had some porous structures on the surface. PO-2-C-H and PO-6-C-H had some wrinkles underneath the film. PO-6-C15-H had some wrinkle patterns on the surface of the film. Thickness and weight of all samples did not change much during the exposure. 
Table 10. Film formation of specialty coatings

\begin{tabular}{|c|c|c|c|}
\hline Formulation & Materials & $\begin{array}{c}\text { Curing } \\
\text { conditions }\end{array}$ & Thickness $(\mu \mathrm{m})$ \\
\hline \multirow{8}{*}{$\mathrm{PO}$} & \multirow{4}{*}{$2 \mathrm{wt} \%$ tBPO in Polyoil 130} & $\begin{array}{c}100^{\circ} \mathrm{C} \text { for } \\
30 \mathrm{~min}\end{array}$ & $37(\mathrm{PO}-2)$ \\
\hline & & $200^{\circ} \mathrm{C}$ for & $21(\mathrm{PO}-2-\mathrm{C}-\mathrm{L})$ \\
\hline & & 30min & 51(PO-2-C-M) \\
\hline & & & 92(PO-2-C-H) \\
\hline & \multirow{4}{*}{$6 w t \%$ tBPO in Polyoil 130} & $\begin{array}{c}100^{\circ} \mathrm{C} \text { for } \\
30 \mathrm{~min}\end{array}$ & 29 (PO-6) \\
\hline & & $200^{\circ} \mathrm{C}$ for & $12(\mathrm{PO}-6-\mathrm{C}-\mathrm{L})$ \\
\hline & & $30 \mathrm{~min}$ & $36(\mathrm{PO}-6-\mathrm{C}-\mathrm{M})$ \\
\hline & & & 99(PO-6-C-H) \\
\hline \multirow{4}{*}{$\mathrm{PB}$} & $\begin{array}{c}2 \mathrm{wt} \% \text { tBPO in Polyoil 130: } \\
\text { polychloroprene }(35: 5)\end{array}$ & $\begin{array}{l}200^{\circ} \mathrm{C} \text { for } \\
30 \mathrm{~min}\end{array}$ & $\begin{array}{l}19(\mathrm{~PB}-2-\mathrm{C} 5-\mathrm{L}) \\
36(\mathrm{~PB}-2-\mathrm{C} 5-\mathrm{M}) \\
87(\mathrm{~PB}-2-\mathrm{C} 5-\mathrm{H})\end{array}$ \\
\hline & $\begin{array}{l}2 \mathrm{wt} \% \text { tBPO in Polyoil 130: } \\
\text { polychloroprene }(25: 15)\end{array}$ & $\begin{array}{l}200^{\circ} \mathrm{C} \text { for } \\
30 \mathrm{~min}\end{array}$ & $\begin{array}{l}36 \text { (PB-2-C15-L) } \\
62(\mathrm{~PB}-2-\mathrm{C} 15-\mathrm{M}) \\
94(\mathrm{~PB}-2-\mathrm{C} 15-\mathrm{H})\end{array}$ \\
\hline & $\begin{array}{c}6 \mathrm{wt} \% \text { tBPO in Polyoil 130: } \\
\text { polychloroprene }(35: 5)\end{array}$ & $\begin{array}{l}200^{\circ} \mathrm{C} \text { for } \\
30 \mathrm{~min}\end{array}$ & $\begin{array}{l}44(\mathrm{~PB}-6-\mathrm{C} 5-\mathrm{L}) \\
67(\mathrm{~PB}-6-\mathrm{C} 5-\mathrm{M}) \\
124(\mathrm{~PB}-6-\mathrm{C} 5-\mathrm{H})\end{array}$ \\
\hline & $\begin{array}{l}6 w t \% \text { tBPO in Polyoil 130: } \\
\text { polychloroprene }(25: 15)\end{array}$ & $\begin{array}{l}200^{\circ} \mathrm{C} \text { for } \\
30 \mathrm{~min}\end{array}$ & $\begin{array}{l}21 \text { (PB-6-C15-L) } \\
72(\text { PB-6-C15-M) } \\
151(\text { PB-6-C15-H) }\end{array}$ \\
\hline
\end{tabular}




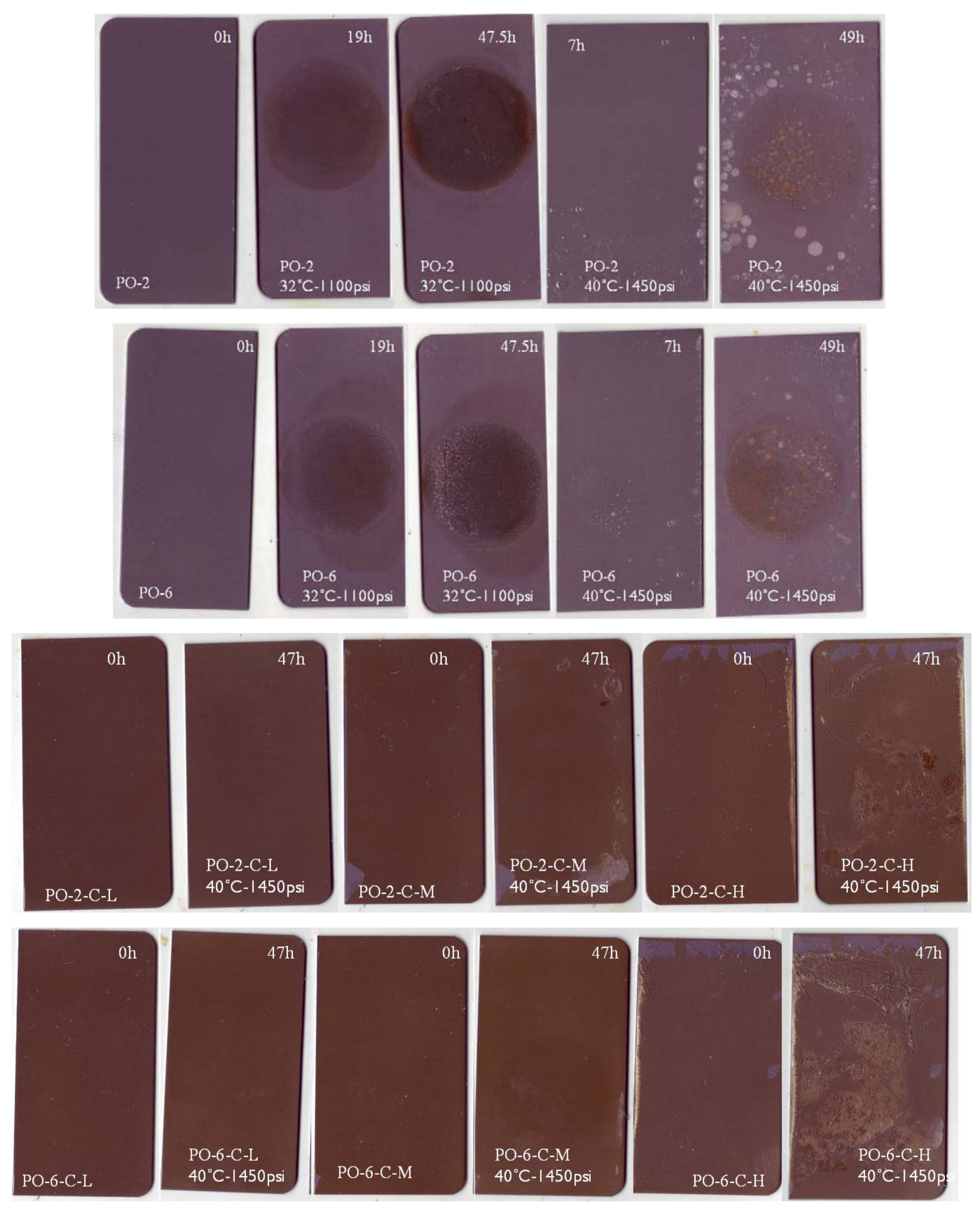



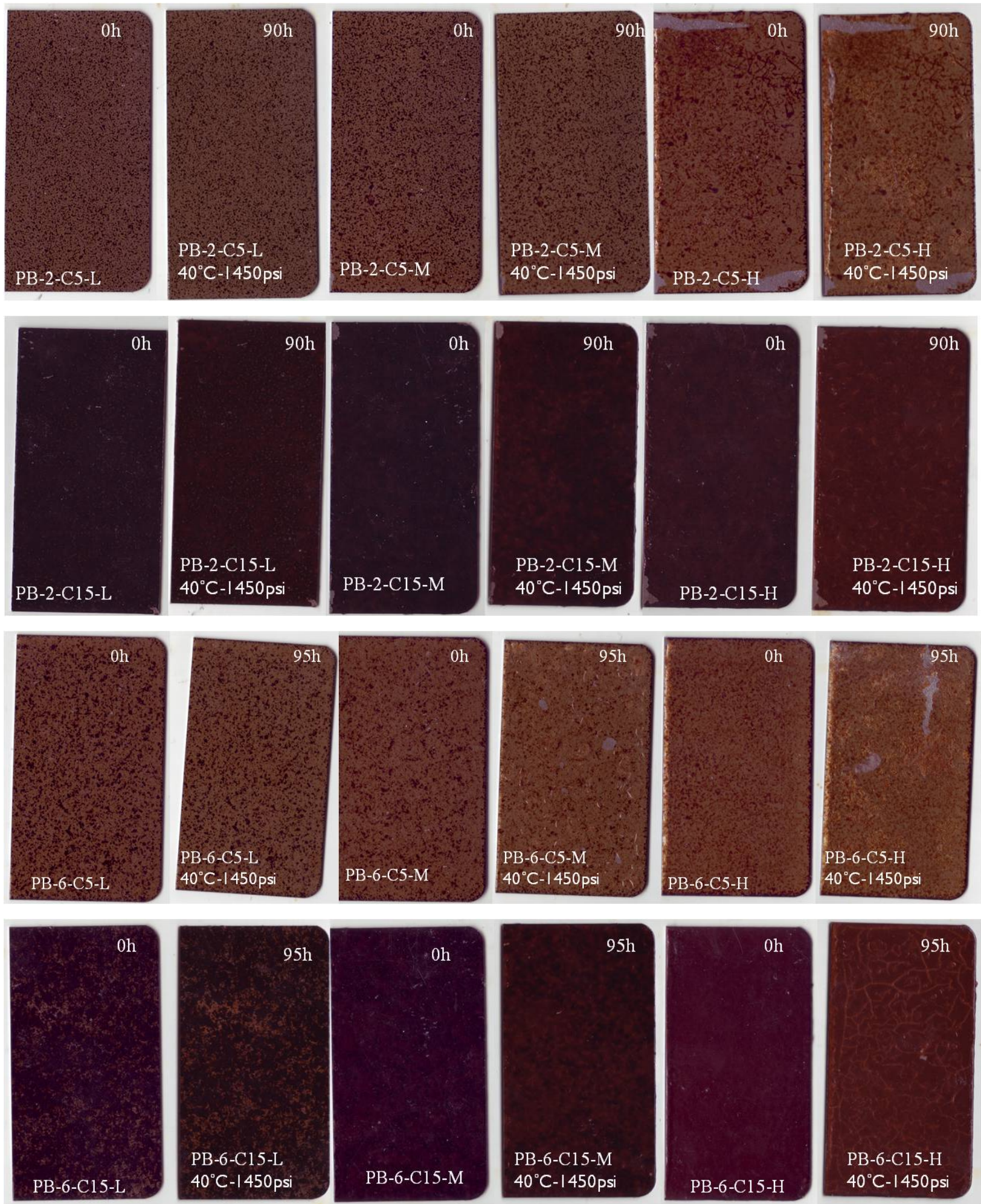

Figure 15. Coated panels with different exposure time to SCCO2. 
Electrochemical impedance spectroscopy is shown in Figure 16. For PO-2 and PO-6 samples, with the exposure time increasing, the impedances decreased, which showed that the coatings deteriorated within the time. However, the impedance increased even higher than the original coating for PO-2 sample after 47.5 hours exposure to $\mathrm{SCCO} 2$ of $32^{\circ} \mathrm{C}$ and 1100 psi. For PO-2-C and PO-6-C samples, the coatings are cured at a higher temperature than the coatings of PO-2 and PO-6 samples. For PO-2-C-L, PO-2-C-M, PO-6-C-L, and PO-6-C-M samples, the impedance did not change too much, which showed a good resistant to SCCO2. However, for PO-2-C-H and PO-6-C-H samples, which were the thicker samples, the impedance decreased a lot due to the exposure to $\mathrm{SCCO} 2$. The reason may be due to the stress released causing the surface delamination or damages. For PB-2-C5 samples, the same trends happened as the PO-2$\mathrm{C}$ and PO-6-C samples, where the thinnest and the thinner samples had almost the same impedance, and the thickest sample had decreased impedance with the increased exposure time. For PB-2-C15 samples, only the thinnest sample kept the impedance, while the thicker and the thickest samples had the decreased impedances. PB-6-C5 and PB-6-C15 had the same trends with PB-2-C5 and PB-2-C15 samples, respectively.
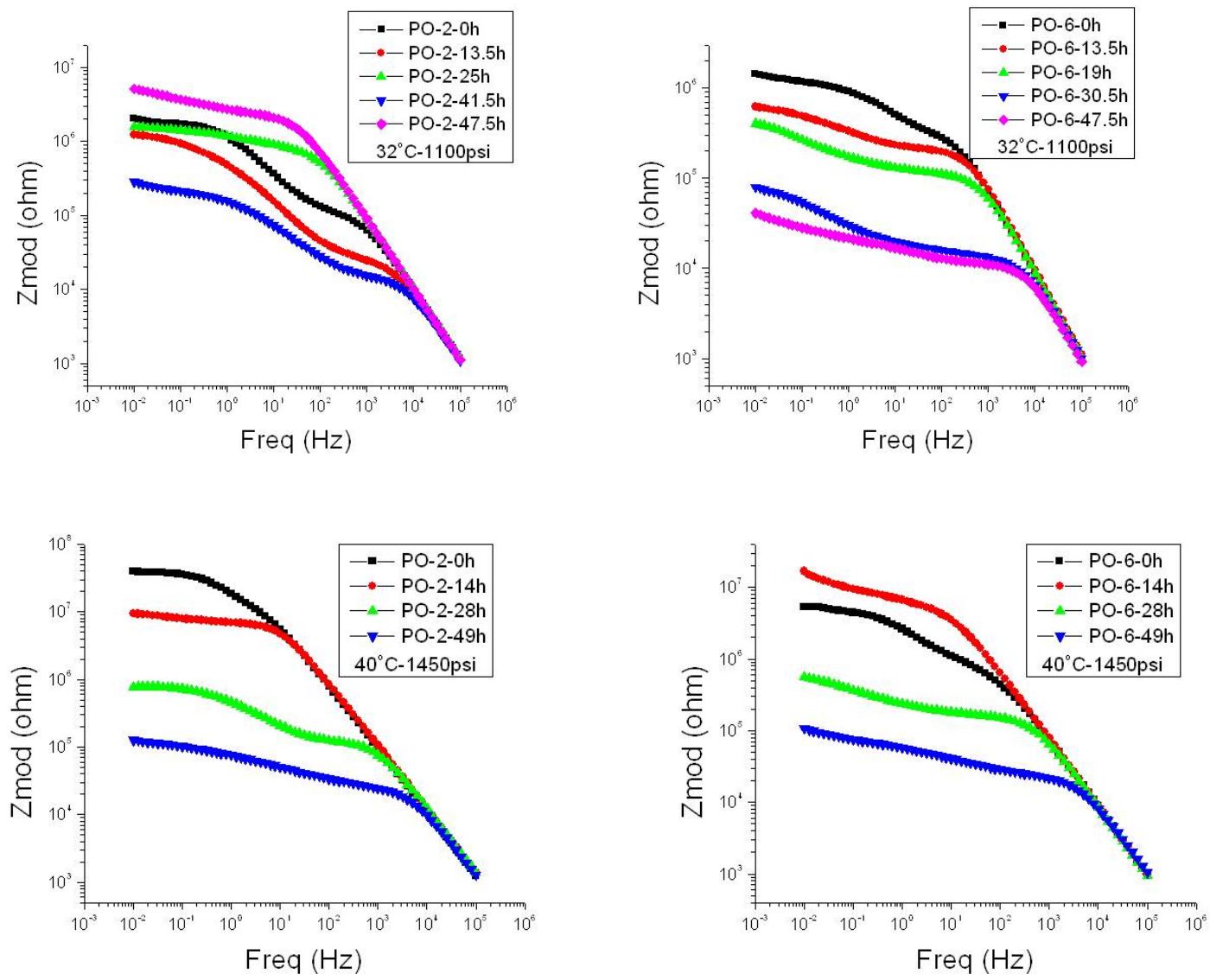

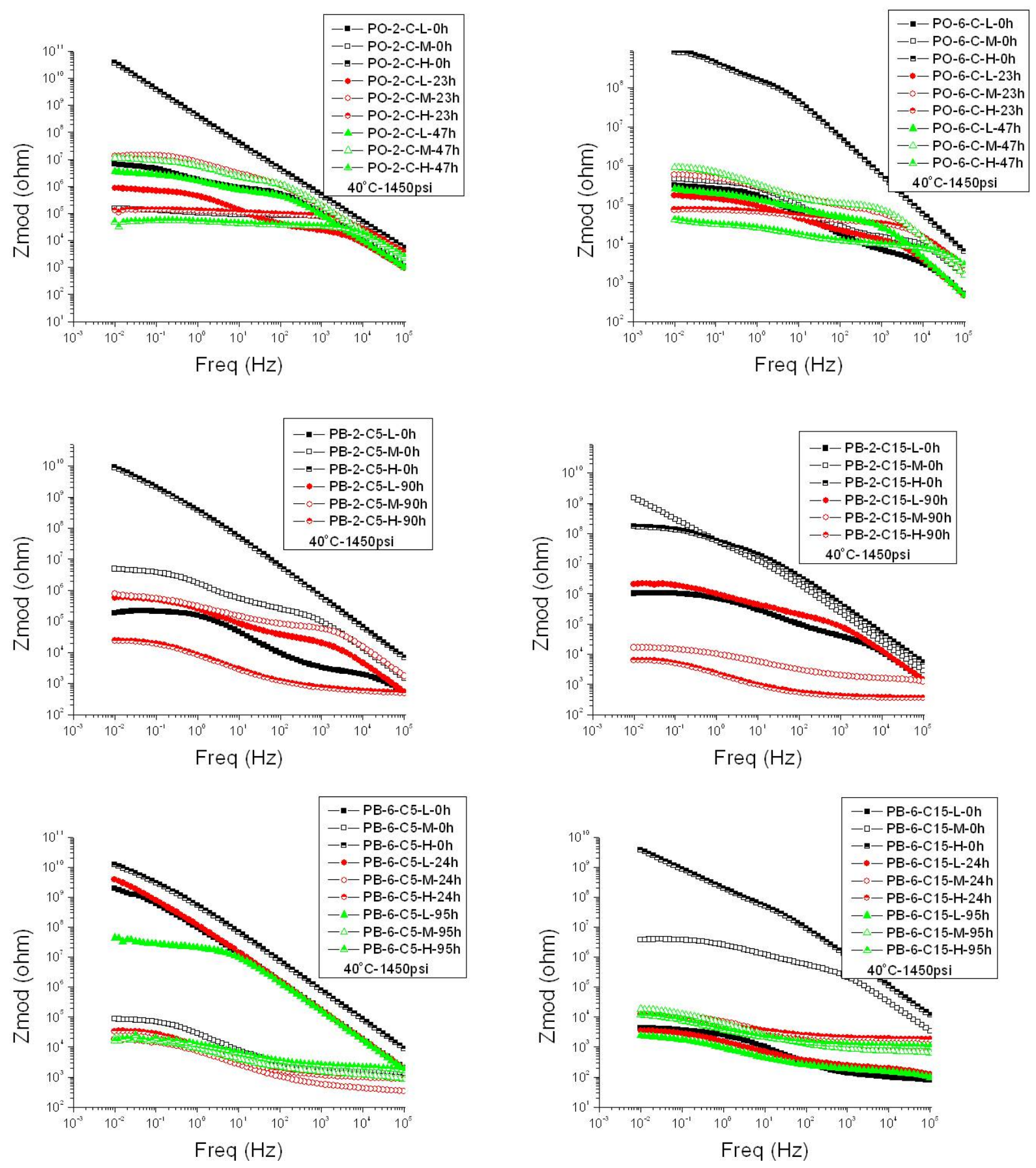

Figure 16. Electrochemical impedance spectroscopy of specialty coatings with various exposure periods.

Results and discussions

The blistering underneath the coating may be caused by the following mechanism (Figure 17). Blister formation occurs when the coating no longer releases $\mathrm{CO} 2$ and returns to having 
barrier film properties after being made very permeable by exposure to SCCO2. From the blister formation, it could be seen that the diffusion coefficient of the coatings returns to a low value, especially for the $\mathrm{CO}_{2}$ gas. The results showed blister formed on the surface of the thickest coatings in each coating systems, due to the diffusion length was the longest to make it the most difficult to diffuse out. The porous structure formed due to the brittleness of the coating causing the blister to rupture and to form pores on the surface. The thinner coatings happened to have more pores on the surface, due to the poorer mechanical properties. With the mechanism, adhesion force is very important to maintain the integrity of the coating film. Drawdown film was more vulnerable for blister formation than spray coating due to the lower adhesion force. Higher pressure and higher temperature can make the diffusivity easier, which are also easier for the blister formation.

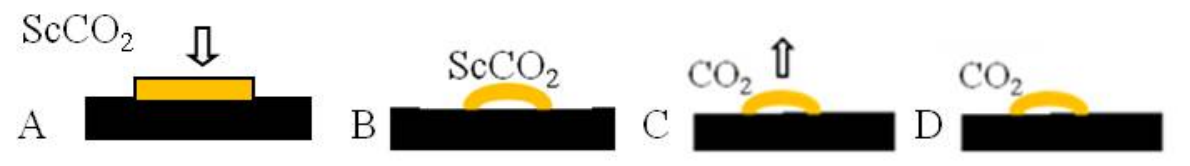

Figure 17. Proposed mechanism of blister formation. A. SCCO2 diffuses into the coatings. B. $\mathrm{SCCO} 2$ saturates the coating. C. $\mathrm{CO}_{2}$ diffuses out of the coatings when pressure is reduced to atmospheric pressure. D. Remaining $\mathrm{CO}_{2}$ changes into gaseous phase and causes blistering with extreme volume increase.

Polymer structures will affect the final properties of the coating films, such as glass transition temperature, brittleness, flexibility, as well as barrier and diffusion properties. Electrochemical impedance measurement can also reflect the coating properties. The plasticizer effect has been done to the performance of epoxy coatings with EIS measurement ${ }^{52}$, where up to $6 \%$ water absorption could alter the thermal behavior and electrochemical barrier properties. A review has been done on thermal properties and water absorption to influence electrochemical properties of organic coatings ${ }^{53,54,55}$. Electrochemical properties are affected by polymer variations and the variations in temperature and water content in the polymer. Glass transition temperature of the polymers might be an indicator of the restriction of the polymer ${ }^{56}$, which could affect the ability of resistance to $\mathrm{SCCO} 2^{57}$. The rigidity of the polymer structure will increase the glass transition temperature ${ }^{56}$. Crosslinking is a way to increase the solvent resistance $^{58,59}$, which will also result into the increasing in glass transition temperature ${ }^{59}$. Rigid pigment particles would increase the glass transition temperature as well ${ }^{60}$. Glass transition 
temperature can be obtained by thermal analysis ${ }^{61}$. To help understand these differences in exposure behavior, thermal analysis of the two coating systems was performed. DSC results of the original coatings are shown in Figure 18. From Figure 18, all coating systems except S345 coating have phase transition within the temperature range of $0^{\circ} \mathrm{C}$ and $200^{\circ} \mathrm{C} . \mathrm{TZ}^{\mathrm{TM}} 904$ coating, DevChem $^{\text {TM }} 253$ coating and S323 coating had endothermic peaks. This usually indicates evaporation of the entrapped solvent. The remained solvent could plasticize coating system, which was harmful to the barrier properties. PO-2 and PO-6 coatings had a significant exothermic peak at a temperature above the current curing temperature, which was strong evidence of further crosslinking above the curing temperature. This shows that we need to cure the experimental system at a higher temperature and longer time. The higher crosslinking density as well as higher glass transition temperature should increase the resistance to SCCO2. S345 coating, the coating system of best $\mathrm{SCCO} 2$ resistance, did not exhibit such a phase transition due to its high temperature curing. With the restriction of polymer by pigment iron oxide, S345 coatings could show good resistance to $\mathrm{SCCO} 2^{62}$. Scotchkote TM 345 glass transition temperature was further obtained through dynamic mechanical analysis (DMA) (Figure 19). The test is using tensile measurement of the film with the size around $15 * 5 * 0.4 \mathrm{~mm}$ by DMA Q800. The temperature ranges from the room temperature to $275^{\circ} \mathrm{C}$ with the rate of $5^{\circ} \mathrm{C} / \mathrm{min}$. The glass transition temperature was $167^{\circ} \mathrm{C}$ by the Storage modulus inflection ${ }^{63}$. 


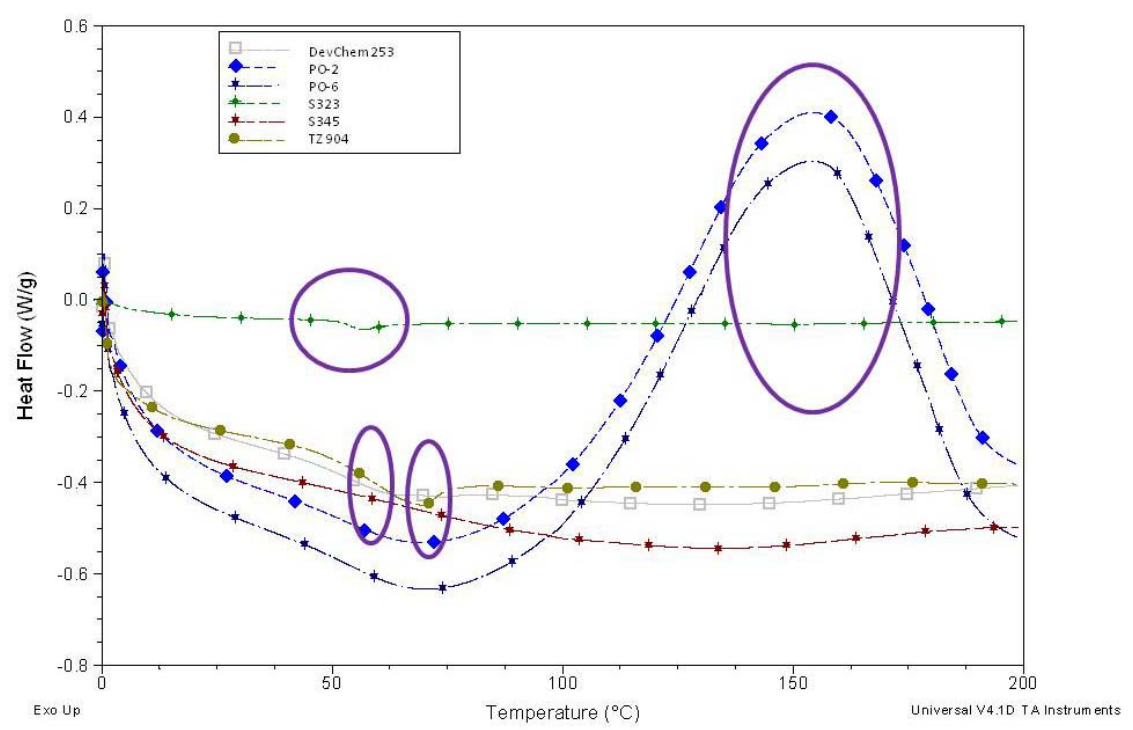

Figure 18. DSC measurement of different coating systems with $20^{\circ} \mathrm{C} / \mathrm{min}$ ramp temperature. The purple circles represent phase transitions.

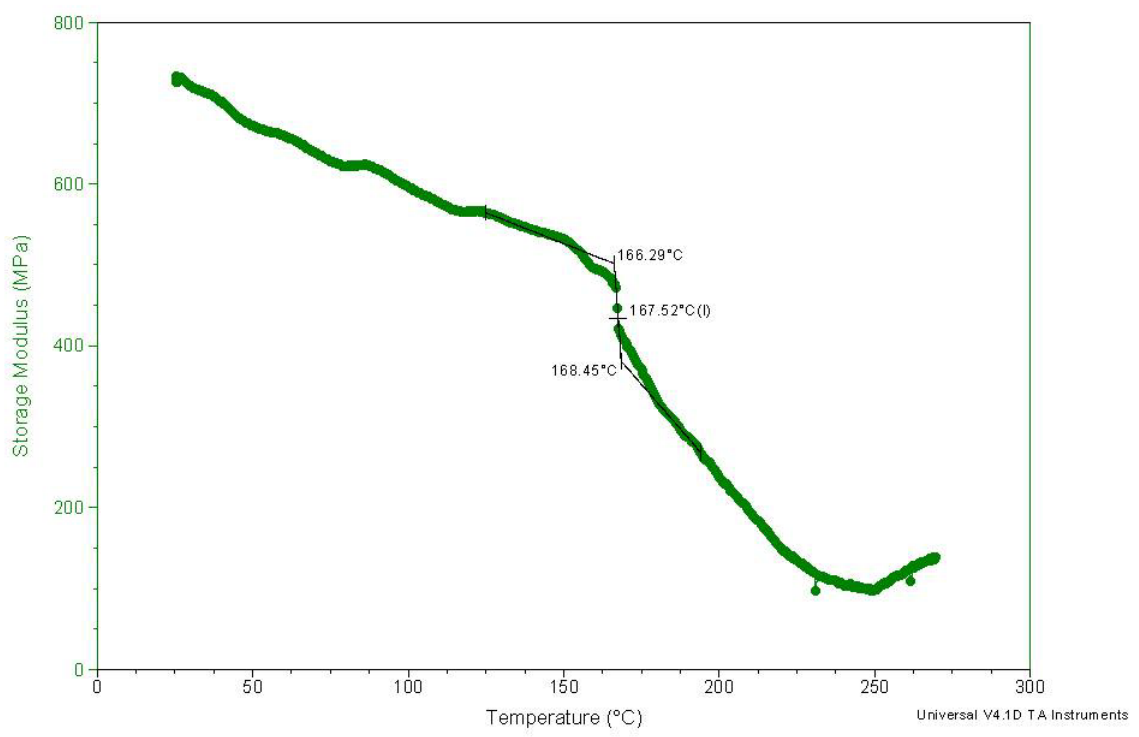

Figure 19. DMA test of Scotchkote ${ }^{\mathrm{TM}} 345$ with $5^{\circ} \mathrm{C} / \mathrm{min}$ ramp temperature.

For Polyoil' ${ }^{\mathrm{TM}}$ 130-based polymers, the higher temperature cured samples PO-2-C and PO-6-C were better than PO-2 and PO-6 samples, due that higher curing temperature promotes higher crosslinking density. PO-6 samples showed a little better than PO-2 samples, due that more initiator promotes higher crosslinking density. PB samples did not show much difference with PO samples. The reason might be phase separation between Polyoil ${ }^{\text {TM }} 130$ and polychloroprene, which was confirmed with the fact that the more polychloroprene, the higher phase separation, and the more coating deterioration. For PB-2-C15 and PB-6-C-15 samples, the 
thicker coatings had more prominent deterioration with exposure to $\mathrm{SCCO} 2$, due to higher internal stress caused by curing process. Internal stress will be released to cause porous structure or patterned structure. Curing condition is important to coating properties as well as to influence barrier properties to $\mathrm{SCCO} 2$. With limited time, curing condition influence on resistance to $\mathrm{SCCO} 2$ was not fully investigated.

\section{Conclusion}

With the investigation, 3M Scotchkote ${ }^{\mathrm{TM}}$ Liquid Phenolic Primer 345 has been proved a good candidate to transport $\mathrm{SCCO} 2$ at various pressure and temperature when thickness of coating is above $50 \mu \mathrm{m}$. Designed Polyoil ${ }^{\mathrm{TM}}$ 130-based polymer systems PO-2-C and PO-6-C, which were cured at $200^{\circ} \mathrm{C}$, showed a good candidate too, when thickness of coatings are around $50 \mu \mathrm{m}$.

During the project, different coating systems and various exposure conditions have been investigated. Following conclusions can be obtained.

1. Four commercial coatings and one designed coating system have been studied to show the sequence of the ability to resistance SCCO2, Commercial coating S345> Designed Polyoil ${ }^{\mathrm{TM}}$ 130-based coating systems $>$ Commercial TZ ${ }^{\mathrm{TM}} 904$ coating $\sim$ Commercial S323 coating $\sim$ Commercial DevChem ${ }^{\mathrm{TM}} 253$ coating. The reason may be due to thermal properties of coating systems. TZ ${ }^{\mathrm{TM}} 904, \mathrm{~S} 323$, and DV 253 coating all had phase transition at the temperature range of $20-200^{\circ} \mathrm{C}$.

2. Blister formation was due to diffusivity of $\mathrm{SCCO} 2$ and $\mathrm{CO}_{2}$, while porous structure formed when coatings were not resilient to stand for pressure in blisters. Blister formed easier with thicker coating, higher temperature of $\mathrm{SCCO} 2$, and higher pressure of $\mathrm{SCCO} 2$. Porous structure formed easier with thinner coating, higher temperature of $\mathrm{SCCO} 2$, higher pressure of $\mathrm{SCCO} 2$, and more brittle coating. Increasing interfacial adhesion would decrease blister formation and porous structure formation.

3. Curing conditions will affect barrier properties of coatings. More initiator and higher curing temperature would increase crosslinking density, which will increase barrier properties. Internal stress caused by curing process, especially for thick coatings, would be harmful to barrier properties and to properties of resistance to SCCO2. Phase separation of blend coatings would be also harmful to barrier properties. 


\section{Appendix 1:}

Dynamical mechanical measurements (DMA) of all used coating systems are shown in Figure 1. It could be seen that Scotchkote ${ }^{\mathrm{TM}} 345$ had a highest glass transition temperature at $167^{\circ} \mathrm{C}$. The other coatings had glass transition temperature less than $100^{\circ} \mathrm{C}$. Storage modulus is related to the stiffness, which is related to free volume ${ }^{64}$. Organic coating with highest glass transition temperature had less free volume, which was difficult for SCCO2 diffusivity. Another interesting found was that Scotchkote 345 and Polyoil ${ }^{\mathrm{TM}} 130$ based coatings both had less modulus change with temperature. Elastic modulus changes depend on crosslinking density, with higher crosslinking density showing less elastic modulus decrease by temperature rise ${ }^{65}$. The higher crosslinking density made the two coatings resistance to SCCO2 and to be used as internal coatings ${ }^{66}$.

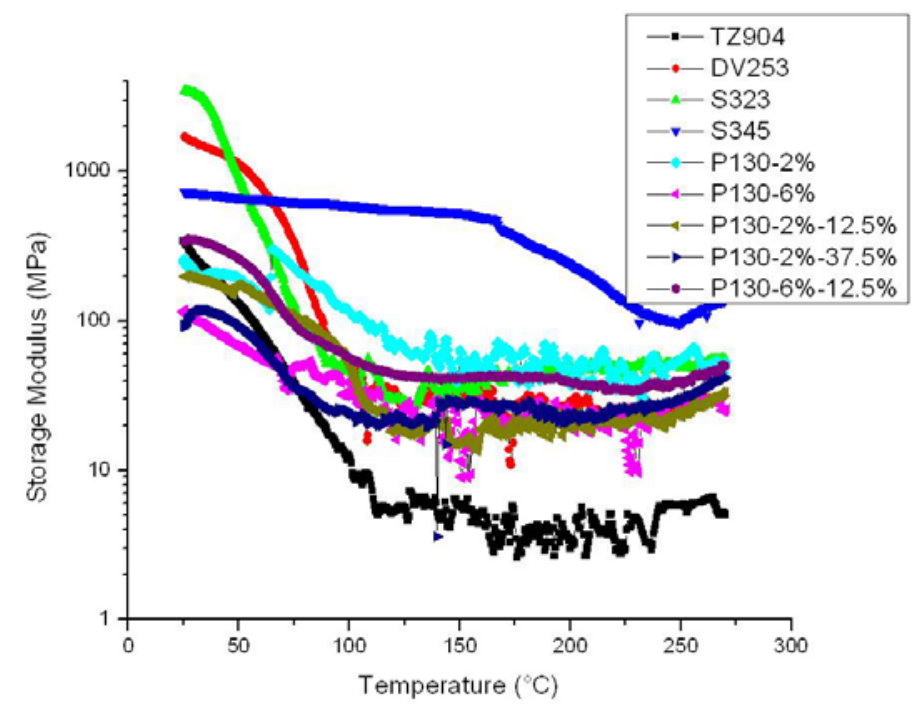

Figure 1. DMA test of coating systems with $5^{\circ} \mathrm{C} / \mathrm{min}$ ramp temperature.

\footnotetext{
${ }^{1}$ Barrie J, Brown K, Hatcher PR et al., Carbon dioxide pipelines: A preliminary review of design and risks, Greenhouse Gas Control Technologies 7, 2005, Vancouver, Canada.

${ }^{2}$ Thomas DC, Benson SM, Impact of SOx and NOx in flue gas on CO2 separation, compression, and pipeline transmission, Carbon Dioxide Capture for Storage in Deep Geologic Formations, 2(2005), 955-981.

${ }^{3}$ Song FM, A comprehensive model for predicting $\mathrm{CO} 2$ corrosion rate in oil and gas production and transportation systems, Electrochimica Acta, 55(2010), 689-700.
} 


\footnotetext{
${ }^{4}$ Seiersten M, Kongshaug KO, Materials selection for capture, compression, transport and injection of CO2, Carbon Dioxide Capture for Storage in Deep Geological Formations, 2(2005), 937-953.

${ }^{5}$ Bratfos HA, Leinum BH, Torbergsen LE et al., Challenges to the pipeline transportation of dense CO2, Journal of Pipeline Engineering, 6(2007), 161-172.

${ }^{6}$ Nesic S, Key issues related to modeling of internal corrosion of oil and gas pipelines-A review, Corrosion Science, 49(2007), 4308-4338.

${ }^{7}$ de Visser E, Hendriks C, Barrio M et al., Dynamic CO2 quality recommendations, International Journal of Greenhouse Gas Control, 2008, 2, 478-484

${ }^{8}$ Vandeginste V, Piessens K, Pipeline design for a least-cost router application for $\mathrm{CO} 2$ transport in the $\mathrm{CO} 2$ sequestration cycle, International Journal of Greenhouse Gas Control, 2008, 2, 571-581

${ }^{9}$ Nazari MH, Allahkaram SR, The effect of acetic acid in the CO2 corrosion of grade X70 steel, Materials and Design, 2010, 31, 4290-4295

${ }^{10}$ Farelas F, Galicia M, Brown B et al., Evolution of dissolution processes at the interface of carbon steel corroding in a CO2 environment studied by EIS, Corrosion Science, 52(2010), 509-517.

${ }^{11}$ Akasaki H, Progress in pipe and tube technology and its future prospect: Application and manufacturing, Nippon Steel Technical Report, No. 90, July 2004.

${ }^{12}$ Woo BH, Sone M, Shibata Aet al., Impregnation of Ni-P metal into polymer substrate via catalyzation in Sc-CO2 and electroless plating in Sc-CO2 emulsion, Surface \& Coatings Technology, 2010, 204, 1785-1792

${ }^{13}$ Lastoskie C, Caging Carbon Dioxide, Science, 2010, 330, 595-596

${ }^{14}$ Mohamed MF, Nor AM, Suhor MFet al., Water chemistry for corrosion prediction in high pressure CO2 environments, NACE Corrosion 2011 Conference \& Expo, 11375

${ }^{15}$ Zheng YC, Gao KW, Schmitt G,Water effect on steel under supercritical CO2 condition, NACE Corrosion 2011 Conference \& Expo, 11378

${ }^{16}$ Zheng YC, Gao KW, Schmitt G, Inhibition of steel corrosion under aqueous supercritical CO2 conditions, NACE Corrosion 2011 Conference \& Expo, 11378

${ }^{17}$ Han JB, Carey JW, Zhang JS, Effect of debonded interfaces on corrosion of mild steel composites in supercritical CO2-saturated brines, NACE Corrosion 2011 Conference \& Expo, 11376

${ }^{18}$ Choi YS, Nesic S, Effect of water content on the corrosion behavior of carbon steel in supercritical CO2 phase with impurities, NACE Corrosion 2011 Conference \& Expo, 11377

${ }^{19}$ Beck J, Lvov S, Fedkin M et al., Electrochemical system to study corrosion of metals in supercritical CO2 fluids, NACE Corrosion 2011 Conference \& Expo, 11380

${ }^{20} \mathrm{Lu}$ S, Wang Z, "Macro-cell current measured by tower-type sensor in chloride-contaminated mortar", IEEE Sensors Journal, 11(2011), 1711-1712.

${ }^{21} \mathrm{Lu}$ SA, Ba HJ, "Corrosion risk assessment of chloride-contaminated concrete structures using embeddable multicell sensor system”, Journal of Central South University of Technology, 18(2011), 230-237.

${ }^{22}$ Qi X, Hinderliter B, Gelling VJ, "Two-electrode electrochemical impedance sensor: Part 1-Response to coating degradation on conductive substrates", Corrosion, 65(2009), 343-349.

${ }_{23}$ Aiello L, Agarwala V, "Galvanic sensor for monitoring structure damage", Corrosion Reviews, 25(2007), 39-50.

${ }^{24}$ Wang DH, Battocchi D, Allahar KN et al., "In sity monitoring of a Mg-rich primer beneath a topcoat exposed to Prohesion conditions", Corrosion Science, 52(2010), 441-448.

${ }^{25}$ Allahar KN, Upadhyay V, Bierwagen GP et al., "Monitoring of a military vehicle coating under Prohesion exposure by embedded sensors", Progress in Organic Coatings, 65(2009), 142-151.

${ }^{26} \mathrm{Wu}$ J, Wu WC, "Study on wireless sensing for monitoring the corrosion of reinforcement in concrete structures", Measurement, 43(2010), 375-380.

${ }^{27} \mathrm{Hu}$ WB, Cai HL, Yang MH et al., "Fe-C-coated fiber Bragg grating sensor for steel corrosion monitoring", Corrosion Science, 53(2011), 1933-1938.

${ }^{28}$ Mrad N, Liu Z, Kobayashi M et al., "Exfoliation detection using structurally integrated piezoelectric ultrasonic transducers", Insight, 48(2006), 738-742.

| ${ }^{29}$ Guo D, Kundu T, “A new sensor for pipe inspection by 1 Lamb waves”, Materials Evaluation, 58(2000), 991-994.

${ }^{30}$ Rumiche F, Indacochea JE, Wang ML, "Detection and monitoring of corrosion in structure carbon steels using electromagnetic sensors", Journal of Engineering Materials and Technology, 130(2008), 031008.

${ }^{31}$ Cho SH, Yoo HR, Rho YW et al., "Feasibility study on the utilization of EMAT technology for in-line inspection of gas pipeline", Journal of Magnetics, 16(2011), 36-41.

${ }^{32}$ Panova AA, Pantano P, Walt DR, "In situ fluorescence imaging of localized corrosion with a pH-sensitive imaging fiber”, Analytical Chemistry, 69(1997), 1635-1641.
} 
${ }^{33}$ Borisov SM, Seifner R, Klimant I, "A novel planar optical sensor for simultaneous monitoring of oxygen, carbon dioxide, pH and temperature", Analytical and Bioanalytical Chemistry, 400(2011), 2463-2474.

${ }^{34}$ Thomas DC, Benson SM, "Impact of SOx and NOx in flue gas on CO2 separation, compression, and pipeline transmission", Carbon Dioxide Capture for Storage in Deep Geologic Formations, 2(2005), 955-981.

${ }^{35}$ Strobel P, Lfakir A, Siadat M et al., "Detection of three pollutant gases and their mixtures in a humid atmosphere using a portable electronic nose", Sensor Letters, 4(2006), 222-228.

${ }^{36}$ Tomasko DL, Li HB, Liu DH et al., A review of CO2 applications in the processing of polymers, Ind. Eng. Chem. Res., 42(2003), 6431-6456.

${ }^{37}$ Bray CL, Tan B, Wood CD et al., High throughput solubility measurements of polymer libraries in supercritical carbon dioxide, Journal of Materials Chemistry, 15(2005), 456-459.

${ }^{38}$ Canelas DA, Burke ALC, DeSimone JM, Carbon dioxide as a continuous phase for polymer synthesis, Plastics Engineering, 53(1997), 37-40.

${ }^{39} \mathrm{Li}$ YG, Park CB, Li HB et al., Measurement of the PVT property of PP/CO2 solution, Fluid Phase Equilibria, 270(2008), 15-22.

${ }^{40}$ Sawan SP, Shieh YT, Su JH, Evaluation of the interaction between supercritical carbon dioxide and polymeric materials, LA-UR-94-2341, (URL: http://www.turi.org/content/view/full/4603)

${ }^{41}$ McCluskey GE, Lee JK, Sha J et al., Synthesis and processing of organic materials in supercritical carbon dioxide, MRS Bulletin, 2009, 34, 108.

${ }^{42}$ Cabanas A, Enciso E, Carbajo MC et al., Effect of supercritical $\mathrm{CO}_{2}$ in modified polystyrene 3D latex arrays, Langmuir, 2006, 22(21), 8966.

${ }^{43}$ Briscoe BJ, Kelly CT, The effect of structure on gas solubility and gas induced dilation in a series of poly(urethane) elastomers, Polymer, 1996. 37(15), 3405

${ }^{44}$ Kojima M, Tosaka M, Ikeda Y, Chemical recycling of sulfur-cured natural rubber using supercritical carbon dioxide, Green Chemistry, 6(2004) 84.

${ }^{45}$ Rindfleisch F, DiNoia TP, McHugh MA, Solubility of polymers and copolymers in supercritical CO2, J. Phys. Chem., 100(1996) 15581.

${ }^{46}$ Huang R, Salmen L, Stenberg B, Effects of the type of crosslink on viscoelastic properties of natural rubber, Journal of Polymer Science, Part B: Polymer Physics, 34(1996), 1997-2006.

${ }^{47}$ Bradehl TD, Leverty HW, Smith RL et al., Solventless compounding and coating of non-thermoplastic hydrocarbon elastomers, USP 5539033, Jun. 23, 1996.

${ }^{48}$ Pranee Phinyocheep, Sayan Duan, Ultraviolet-curable liquid natural rubber, Journal of Applied Polymer Science, 78(2000), 1478-1485.

${ }^{49}$ Smith WC, Elizabeth NJ, Adhesion of butyl rubber to metal, USP 2471905, May. 31, 1949

${ }^{50}$ Nagelschmidt R, Rudolph A, Corrosion preventing coating compositions for metals comprising a chlorine containing organic polymer as film former, a copper compound and a tertiary organic heterocyclic base, USP 2860118, Nov. 11, 1958

${ }^{51}$ Burton SA, Ross R, Corrosion protection with elastomers-an investigation of cathodic protection effects on elastomeric coated pipelines and risers, Corros. Prev. Control., 34(1987), 45-50.

${ }_{52}$ Rodríguez MT, Gracenea JJ, García SJ et al., Testing the influence of the plasticizers addition on the anticorrosive properties of an epoxy primer by means of electrochemical techniques, Progress in Organic Coatings, 50 (2004), 123.

${ }^{53}$ Li J, Jeffcoate CS, Bierwagen GP et al., Thermal Transition Effects and Electrochemical Properties in Organic Coatings: Part 1 --- Initial Studies on Corrosion Protective Organic Coatings, Corrosion, 54 (1998), 763.

${ }^{54}$ Bierwagen G, He L, Tallman D, Time-temperature effects in polymer coatings for corrosion protection as analyzed by EIS, Macromolecular Symposia, 187(2002), 909.

${ }_{55}$ Jeffcoate C, Wocken T, Bierwagen G, Electrochemical assessment of spray-applied thermoplastic coating barrier properties, Journal of Materials Engineering and Performance, 6(1997), 417.

${ }^{56}$ Ronova IA, Bruma M, Influence of chemical structure on glass transition temperature of polyimides, Structural Chemistry, 21(2010), 1013-1020.

${ }^{57}$ Briscoe BJ, Kelly CT, The effect of structure on gas solubility and gas induced dilation in a series of poly(urethane) elastomers, Polymer,37(1996),3405-3410.

${ }_{58}$ Patil AO, Coolbaugh TS, Elastomers: A literature review with emphasis on oil resistance, Rubber Chemistry and Technology, 78(2005), 516-535.

${ }^{59}$ Zhang Y, Zhan F, Shi WF, Photopolymerization behavior and properties of highly branched poly(thioetherurethane) acrylates used for UV-curing coatings, Progress in Organic Coatings, 71(2011), 399-405. 
${ }^{60}$ Perera DY, Effect of pigmentation on organic coating characteristics, Progress in Organic Coatings, 50(2004), 247-262.

${ }^{61}$ Sircar AK, Galaska ML, Rodrigues S et al., Glass transition of elastomers using thermal analysis techniques, Rubber Chemistry and Technology, 72(1999), 513-552.

${ }^{62}$ Briscoe BJ, Kelly CT, The effect of structure on gas solubility and gas induced dilation in a series of poly(urethane) elastomers, Polymer,37(1996),3405-3410.

${ }^{63}$ Sims GD, Gnaniah SJP, Improved procedures for the determination of $\mathrm{T}_{\mathrm{g}}$ by dynamic mechanical analysis, $17^{\text {th }}$ International Conference on Composite Materials, 27 Jul 2009-31 Jul 2009, Edinburgh, UK.

${ }^{64}$ Okada T, Nishijima S, Honda Y et al., "Physical properties of epoxy and free volume evaluated by positron annihilation spectroscopy", Journal De Physique IV, 3(1993), 291-294

${ }^{65} \mathrm{http} / / / \mathrm{www}$. files.chem.vt.edu/chem-dept/acs/networks/networks3_2_3.html, accessed on Feb. 13, 2012

${ }^{66}$ Sawan SP, Shieh YT, Su JH, Evaluation of the interaction between supercritical carbon dioxide and polymeric materials, LA-UR-94-2341, (URL: http://www.turi.org/content/view/full/4603) 